\title{
Mixed Convection Heat Transfer for Nanofluids in a Lid-Driven Shallow Rectangular Cavity Uniformly Heated and Cooled from the Vertical Sides: The Cooperative Case
}

\author{
Hassan Elharfi, ${ }^{1}$ Mohamed Naïmi, ${ }^{1}$ Mohamed Lamsaadi, ${ }^{2}$ \\ Abdelghani Raji, ${ }^{1}$ and Mohammed Hasnaoui ${ }^{3}$ \\ ${ }^{1}$ Laboratory of Flows and Transfers Modelling (LAMET), Physics Department, Faculty of Sciences and Technologies, \\ Sultan Moulay Slimane University, BP 523, Beni-Mellal, Morocco \\ ${ }^{2}$ Interdisciplinary Laboratory of Research in Sciences and Technologies (LIRST), Polydisciplinary Faculty, \\ Sultan Moulay Slimane University, BP 592, Beni-Mellal, Morocco \\ ${ }^{3}$ Laboratory of Fluid Mechanics and Energetics (LMFE), Physics Department, Faculty of Sciences Semlalia, \\ Cadi Ayyad University, BP 2390, Marrakech, Morocco
}

Correspondence should be addressed to Mohamed Naïmi, naimima@yahoo.fr

Received 19 September 2012; Accepted 15 October 2012

Academic Editors: R. J. Abergel, M. Manciu, and S. Yulin

Copyright () 2012 Hassan Elharfi et al. This is an open access article distributed under the Creative Commons Attribution License, which permits unrestricted use, distribution, and reproduction in any medium, provided the original work is properly cited.

A study of mixed convection, in a shallow lid-driven rectangular cavity filled with water-based nanofluids and subjected to uniform heat flux along the vertical side walls, has been performed numerically by solving the full governing equations via the finite volume method and the SIMPLER algorithm. In the limit of a shallow enclosure, these equations have been considerably reduced by using the parallel flow approximation. Solutions, for the flow and temperature fields, and the heat transfer rate, have been obtained as functions of the governing parameters, namely, the Reynolds (Re) and the Richardson (Ri) numbers and the solid volume fraction of nanoparticles $(\Phi)$. A good agreement has been obtained between the results of the two approaches for a wide range of the governing parameters. Moreover, it has been found that the addition of $\mathrm{Cu}$-nanoparticles, into the pure water, leads to an enhancement or a degradation of heat transfer depending on the values of Re and Ri.

\section{Introduction}

With conventional fluids, such as water and oil, heat transfer is limited because of their poor thermal conductivity. This is a crucial problem that should be challenging. Also, current design solutions already push available technology to its limits, and an innovative way should be taken. In such a context, Choi [1], of Argonne National Laboratory, developed the novel concept of nanofluids as a route to improve the performances of heat transfer fluids currently available. This new class of advanced heat transfer fluids is engineered by dispersing solid nanoparticles (metallic, nonmetallic, or polymeric), smaller than $100 \mathrm{~nm}$ in diameter, in base fluids (aqueous or organic host liquids), which confers a large thermal conductivity on these ones and makes them potentially useful in engineering equipments involving heat transfer. To know about nanoparticles, nanofluids, their production and applications, see for instance the report of $\mathrm{Yu}$ et al. [2], currently available in http://www.osti.gov/bridge.

During the last decade, nanofluids have attracted lots of researchers encouraged by their critical importance and promising role, as new advanced heat transfer fluids, to take up challenges. Therefore, numerous studies, on convection heat transfer, have been conducted, and most of them have dealt with forced convection, indicating that nanoparticle suspensions have unquestionably a great potential for heat transfer enhancement, as reported in a recent paper by Corcione [3]. In contrast, although the investigations concerned with buoyancy-driven convection are relatively few, they have known a gradual increase lately, leading to contradictory 
findings, thus leaving still unanswered the question if the use of nanoparticle suspensions for natural convection applications is actually advantageous with respect to pure liquids [3]. At the same time, mixed convection has not received either less attention in view of the number of the related works recently done. Among them, flow and heat transfer problem in lid-driven cavities, which finds applications in industrial processes such as food processing, float glass production [4], thermal hydraulics of nuclear reactors [5], dynamics of lakes [6], crystal growth, flow and heat transfer in solar ponds [7], and lubrication technologies [8]. The interaction of the shear-driven flow due to the lid motion and natural convective flow due to the buoyancy effect is quite complex, which necessitates a comprehensive analysis to understand the physics of the resulting flow and heat transfer process. In this respect, different configurations and combinations of thermal and dynamical boundary conditions have been considered and analysed by some investigators. The contributions can be divided in two cases.

(i) Steady state case where all boundary conditions are time independent. In this regard, it is advisable to mention the work of Tiwari and Das [8], who studied heat transfer enhancement in a nanofluid-filled square cavity, with the vertical sides moving and differentially heated, while the horizontal ones are insulated and motionless. Three situations, depending on the direction of the moving walls, were examined, and a model taking into account the solid volume fraction of nanoparticles was developed to analyse the nanofluids behaviour. With only one uniformly moving wall, from left to right, first, it is to bring up the research of Abu-Nada and Chamkha [9] dealing with mixed convection flow in an inclined square enclosure filled with a nanofluid. The left and right walls are kept insulated while the bottom and the moving top ones are maintained at constant cold and hot temperatures, respectively. It was found that significant heat transfer enhancement can be obtained due to the presence of nanoparticles and that this is accentuated by inclination of the enclosure at moderate and large Richardson numbers. Mahmoodi [10] investigated mixed convection fluid flow and heat transfer in rectangular enclosures filled with a nanofluid. The left and right walls as well as the top one are maintained at a constant cold temperature. The moving bottom is kept at a constant hot temperature. A parametric study was performed and the effects of the Richardson number, the aspect ratio of the enclosure and the volume fraction of the nanoparticles on the fluid flow and heat transfer were analysed. It was found that, for the selected values of the Richardson number, the average Nusselt number increases with the nanoparticles volume fraction and seems to be higher with tall enclosures than with shallow ones. In the case of a nanofluid-filled square cavity with cold sides, a partially heated (with constant heat flux heater) and insulated bottom, and a moving cold top, Mansour et al. [11] examined the effects of the Reynolds number, the type of nanofluids, the size and location of the heater and the volume fraction of the nanoparticles in their study related to mixed convection. They observed that the heat transfer enhances with all the abovementioned parameters. Muthtamilselvan et al. [12] studied heat transfer enhancement of nanofluids in rectangular enclosures, where the moving top is at higher constant temperature than the bottom whereas the left and right boundaries are insulated. They found that at higher aspect ratios, the heat transfer rate increases strongly with the nanoparticles volume fraction. Nemati et al. [13] investigated heat transfer performances of a moving top square cavity, filled with nanofluids and subject to different side wall temperatures. They reported that an increase of nanoparticles volume fraction enhances heat transfer, but such an effect reduces with the Reynolds number. As for Talebi et al. [14], they conducted an investigation on mixed convection flows in a square lid-driven cavity, having left and right sides heated and cooled, respectively, and moving top and bottom both adiabatic, utilising nanofluids. These authors showed that, at given Rayleigh and Reynolds numbers, an increase of the nanoparticles concentration favours the flow and heat transfer. Finally, like Tiwari and Das [8], Sheikhzadeh et al. [15] were interested in laminar mixed convection of a nanofluid in two-sided lid-driven enclosures. The moving left and right walls are maintained at constant cold and hot temperatures, respectively, while the horizontal ones are insulated. The effect of moving direction of walls on mixed convection is studied for various Richardson numbers, aspect ratios, and nanoparticles volume fractions and was found to affect mainly the flow field, temperature gradient, and heat transfer. In addition, increasing the volume fraction of nanoparticles resulted in a linear increase of the average Nusselt number, as an index of heat transfer rate improvement, for all the considered cases.

(ii) Unsteady state case, where some boundary conditions are time dependent as in the only work done, in this subject, by Karimipour et al. [16], where periodic mixed convection of a nanofluid inside a rectangular cavity, with insulted vertical sides and hot temperature bottom kept at rest and cold temperature top horizontally oscillating, was carried out. The effects of Richardson number and volume fraction of nanoparticles on the flow and thermal behaviour of the nanofluid were examined. It was observed that the best heat transfer is obtained with a Richardson number lower than unit and that the higher value of this parameter corresponds to the lower amplitude of the oscillation of the heat transfer rate in the steady periodic state. In addition, heat transfer was found to be improved by nanoparticles presence. 
All the above-mentioned studies are of numerical nature, using a finite volume method (for the most), a finite difference method, or Lattice Boltzmann method to solve the governing equations and various single-phase models to describe effective conductivity and viscosity of the considered nanofluids, which are principally $\mathrm{Al}_{2} \mathrm{O}_{3}$ or $\mathrm{Cu}$-water.

As we know, the problem of mixed convection heat transfer of nanofluids in a lead-driven enclosure subjected to thermal boundary conditions of Neumann type (i.e., heat fluxes imposed to the boundaries) is not yet examined. So, in order to know more about the effect of the boundary conditions kind on flow and heat transfer within confined nanofluids, the present paper deals with such a problem within a twodimensional shallow rectangular enclosure, filled with $\mathrm{Cu}-$ water nanofluids, whose short vertical sides are submitted to uniform heat fluxes while the long horizontal ones are maintained adiabatic with the top moving in the direction of the imposed heat flux. A numerical solution of the full governing equations has been obtained via a finite volume method. An analytical one, based on the parallel flow approximation, has been also proposed. The results are presented, in terms of streamlines, isotherms, stream function and temperature profiles and heat transfer rates, and discussed for various values of the dimensionless parameters, controlling the problem, which are the Reynolds, Re, and Richardson, Ri, numbers, and the solid volume fraction of nanoparticles, $\Phi$.

\section{Mathematical Formulation}

The studied configuration is sketched in Figure 1. It is a shallow rectangular enclosure of height $H^{\prime}$ and length $L^{\prime}$, filled with $\mathrm{Cu}$-water nanofluids. The long horizontal walls are adiabatic, while the vertical short ones are submitted to a uniform density of heat flux, $q^{\prime}$. All these boundaries are rigid, impermeable, and motionless apart from the top one which moves in its own plane from left to right at uniform velocity. The main assumptions made here are those commonly used, that is

(i) the base fluid and the nanoparticles are in thermal equilibrium and they flow at the same velocity (i.e., no slip occurs between them or the nanoparticles are uniformly dispersed within the base fluid so that the resulting nanofluid can be considered a single-phase fluid);

(ii) the nanoparticles are spherical;

(iii) the nanofluid is Newtonian and incompressible;

(iv) the thermophysical properties of the considered nanofluids are constant except for the density in the buoyancy term, which obeys the Boussinesq approximation;

(v) the flow is two-dimensional, laminar, and steady;

(vi) the radiation heat transfer between the sides of the cavity is negligible when compared with the other mode of heat transfer.

Therefore, the equations describing the conservation of mass (1), momentum (2)-(3), and energy (4), written in terms of velocity components $\left(u^{\prime}, v^{\prime}\right)$, pressure $\left(p^{\prime}\right)$, and temperature $\left(T^{\prime}\right)$, are

$$
\begin{gathered}
\frac{\partial u^{\prime}}{\partial x^{\prime}}+\frac{\partial v^{\prime}}{\partial y^{\prime}}=0 \\
\frac{\partial u^{\prime}}{\partial t^{\prime}}+u^{\prime} \frac{\partial u^{\prime}}{\partial x^{\prime}}+v^{\prime} \frac{\partial u^{\prime}}{\partial y^{\prime}}=-\frac{1}{\rho_{n f}} \frac{\partial P^{\prime}}{\partial x^{\prime}}+\frac{\mu_{n f}}{\rho_{n f}}\left(\frac{\partial^{2} u^{\prime}}{\partial x^{\prime 2}}+\frac{\partial^{2} u^{\prime}}{\partial y^{\prime 2}}\right) \\
\frac{\partial v^{\prime}}{\partial t^{\prime}}+u^{\prime} \frac{\partial v^{\prime}}{\partial x^{\prime}}+v^{\prime} \frac{\partial v^{\prime}}{\partial y^{\prime}}=-\frac{1}{\rho_{n f}} \frac{\partial P^{\prime}}{\partial y^{\prime}}+\frac{\mu_{n f}}{\rho_{n f}}\left(\frac{\partial^{2} v^{\prime}}{\partial x^{\prime 2}}+\frac{\partial^{2} v^{\prime}}{\partial y^{\prime 2}}\right) \\
+\frac{1}{\rho_{n f}}(\rho \beta)_{n f} g\left(T^{\prime}-T_{0}^{\prime}\right) \\
\frac{\partial T^{\prime}}{\partial t^{\prime}}+u^{\prime} \frac{\partial T^{\prime}}{\partial x^{\prime}}+v^{\prime} \frac{\partial T^{\prime}}{\partial y^{\prime}}=\alpha_{n f}\left(\frac{\partial^{2} T^{\prime}}{\partial x^{\prime 2}}+\frac{\partial^{2} T^{\prime}}{\partial y^{\prime 2}}\right)
\end{gathered}
$$

To close the problem, the following appropriate boundary conditions are applied:

$$
\begin{gathered}
u^{\prime}=v^{\prime}=0, \quad \frac{\partial T^{\prime}}{\partial x^{\prime}}+\frac{q^{\prime}}{k_{n f}}=0 \quad \text { for } x^{\prime}=0, x^{\prime}=L^{\prime}, \\
u^{\prime}=v^{\prime}=0, \quad \frac{\partial T^{\prime}}{\partial y^{\prime}}=0 \quad \text { for } y^{\prime}=0, \\
u^{\prime}-U_{0}^{\prime}=v^{\prime}=0, \quad \frac{\partial T^{\prime}}{\partial y^{\prime}}=0 \quad \text { for } y^{\prime}=H^{\prime} .
\end{gathered}
$$

To model the effective physical properties of the nanofluid, appearing in the above equations, the following formulas are used:

$$
\rho_{n f}=(1-\Phi) \rho_{f}+\Phi \rho_{n p}
$$

for the effective density, as shown in [2];

$$
\mu_{n f}=\frac{\mu_{f}}{(1-\Phi)^{2.5}}
$$

for the effective dynamic viscosity, which is due to Brinkman, [2];

$$
(\rho \beta)_{n f}=(1-\Phi)(\rho \beta)_{f}+\Phi(\rho \beta)_{n p}
$$

for the thermal expansion coefficient [17];

$$
(\rho C p)_{n f}=(1-\Phi)(\rho C p)_{f}+\Phi(\rho C p)_{n p}
$$

for the heat capacity [2];

$$
\frac{k_{n f}}{k_{f}}=\frac{k_{n p}+2 k_{f}-2 \Phi\left(k_{f}-k_{n p}\right)}{k_{n p}+2 k_{f}+\Phi\left(k_{f}-k_{n p}\right)}
$$

for the effective thermal conductivity, due to MaxwellGarnett, which is a restriction of the Hamilton-Crosser model to spherical nanoparticles [2];

$$
\alpha_{n f}=\frac{k_{n f}}{(\rho C p)_{n f}}
$$

for the thermal diffusivity [18]. 


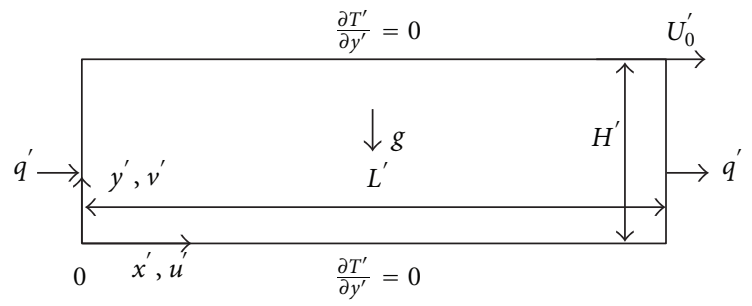

FIGURE 1: Schematic view of the geometry and coordinates system.

On the other hand, using the characteristic scales $H^{\prime}, \rho_{f} U_{0}^{\prime 2}, H^{\prime} / U_{0}^{\prime}, U_{0}^{\prime}$, and $q^{\prime} H^{\prime} / k_{f}$, corresponding to length, pressure, time, velocity, and temperature, respectively, the dimensionless governing equations and the corresponding boundary conditions are

$$
\begin{gathered}
\frac{\partial u}{\partial x}+\frac{\partial v}{\partial y}=0 \\
\frac{\partial u}{\partial t}+u \frac{\partial u}{\partial x}+v \frac{\partial u}{\partial y}=-\frac{1}{\bar{\rho}} \frac{\partial P}{\partial x}+\frac{\bar{v}}{\operatorname{Re}}\left(\frac{\partial^{2} u}{\partial x^{2}}+\frac{\partial^{2} u}{\partial y^{2}}\right) \\
\frac{\partial v}{\partial t}+u \frac{\partial v}{\partial x}+v \frac{\partial v}{\partial y}=-\frac{1}{\bar{\rho}} \frac{\partial P}{\partial y}+\frac{\bar{v}}{\operatorname{Re}}\left(\frac{\partial^{2} v}{\partial x^{2}}+\frac{\partial^{2} v}{\partial y^{2}}\right)+\frac{\bar{\beta}}{\bar{\rho}} \mathrm{Ri} T \\
\frac{\partial T}{\partial t}+u \frac{\partial T}{\partial x}+v \frac{\partial T}{\partial y}=\frac{\bar{\alpha}}{\operatorname{Pe}}\left(\frac{\partial^{2} T}{\partial x^{2}}+\frac{\partial^{2} T}{\partial y^{2}}\right) \\
u=v=\frac{\partial T}{\partial x}+\frac{1}{\bar{k}}=0 \quad \text { for } x=0, A \\
u=v=\frac{\partial T}{\partial y}=0 \quad \text { for } y=0 \\
u-1=v=\frac{\partial T}{\partial y}=0 \quad \text { for } y=1
\end{gathered}
$$

where $\bar{k}=k_{n f} / k_{f}, \bar{\alpha}=\alpha_{n f} / \alpha_{f}, \bar{v}=v_{n f} / v_{f}, \bar{\beta}=$ $(\rho \beta)_{n f} /(\rho \beta)_{f}$, and $\bar{\rho}=\rho_{n f} / \rho_{f}$ are parameters depending on $\Phi$, according to models given above. In addition, to analysis the flow structure, the stream function, $\psi$, related to the velocity components via

$$
u=\frac{\partial \psi}{\partial y}, \quad v=-\frac{\partial \psi}{\partial x} \quad \text { (with } \psi=0 \text { on all boundaries) }
$$

is used.

The above equations give rise to some dimensionless parameters that govern the problem, namely, the solid volume fraction $\Phi$, the aspect ratio of the enclosure, $A$, the Peclet, Pe, Reynolds, Re, and Richardson, Ri, numbers. For the last four, the expressions are

$$
\begin{aligned}
A=\frac{L^{\prime}}{H^{\prime}}, \quad \mathrm{Pe} & =\frac{U_{0}^{\prime} H^{\prime}}{\alpha_{f}}, \quad \mathrm{Re}=\frac{U_{0}^{\prime} H^{\prime}}{\nu_{f}}, \\
\mathrm{Ri} & =\frac{g \beta_{f} q^{\prime} H^{\prime 2}}{k_{f} U_{0}^{\prime 2}} .
\end{aligned}
$$

Note that

$$
\mathrm{Pe}=\mathrm{Pr} \mathrm{Re}, \quad \mathrm{Ri}=\frac{\mathrm{Gr}}{\mathrm{Re}^{2}}=\frac{\mathrm{Ra}}{\mathrm{Pe} \mathrm{Re}},
$$

where

$$
\mathrm{Gr}=\frac{g \beta_{f}^{\prime} q^{\prime} H^{\prime 4}}{v_{f}^{2} k_{f}}, \quad \operatorname{Pr}=\frac{v_{f}}{\alpha_{f}}, \quad \mathrm{Ra}=\operatorname{Pr} \mathrm{Gr}
$$

are the Grashof, Prandtl, and Rayleigh numbers, respectively.

The local heat transfer, through the nanofluid-filled cavity, can be expressed in terms of the local Nusselt number defined as

$$
\mathrm{Nu}(y)=\frac{h L^{\prime}}{k_{f}}=\frac{q^{\prime}}{\Delta T^{\prime}} \frac{L^{\prime}}{k_{f}}=\frac{L^{\prime}}{H^{\prime}} \frac{\Delta T^{*}}{\Delta T^{\prime}}=\frac{A}{\Delta T}=\frac{1}{\Delta T / A},
$$

where $h$ is the heat exchange coefficient, $\Delta T^{*}=q^{\prime} H^{\prime} / k_{f}$ a characteristic temperature, and $\Delta T=T(0, y)-T(A, y)$ the side-to-side dimensionless local temperature difference. This definition is based on the thermal conductivity of the base fluid, $k_{f}$, which seems logical since, according to Corcione [3], Nu that would describe the thermal performance of the enclosure, with immediacy, should vary in the same manner as $h$ and vice versa. However, (23) is notoriously inaccurate owing to the uncertainty of the temperature values evaluated at the two vertical walls (edge effects). Instead, $\mathrm{Nu}$ is calculated on the basis of a temperature difference between two vertical sections, far from the end sides, as suggested by Lamsaadi et al. [19]. Thus, by analogy with (23), and considering two infinitesimally close sections, $\mathrm{Nu}$ can be expressed by

$$
\mathrm{Nu}(y)=\lim _{\delta x \rightarrow 0} \frac{\delta x}{\delta T}=\lim _{\delta x \rightarrow 0} \frac{1}{(\delta T / \delta x)}=-\frac{1}{(\partial T / \partial x)_{x=A / 2}},
$$

where $\delta x$ is the distance between two symmetrical sections with respect to the central one. The corresponding average Nusselt number is calculated, at different locations, from

$$
\overline{\mathrm{Nu}}=\int_{0}^{1} \mathrm{Nu}(y) d y .
$$




\section{Numerics}

Equations (12)-(15) associated with (16)-(18) have been solved by using a finite volume method and SIMPLER algorithm in a staggered uniform grid system [20]. A second order backwards finite difference scheme has been employed to discretize the temporal terms appearing in (13)-(15). A line-by-line tridiagonal matrix algorithm with relaxation has been used in conjunction with iterations to solve the nonlinear discretized equations. The convergence has been considered as reached when $\sum_{i, j}\left|f_{i, j}^{k+1}-f_{i, j}^{k}\right|<$ $10^{-5} \sum_{i, j}\left|f_{i, j}^{k+1}\right|$, where $f_{i, j}^{k}$ stands for the value of $u, v, p$, or $T$ at the $k$ th iteration level and grid location $(i, j)$ in the plane $(x, y)$. The mesh size has been chosen so that a best compromise between running time and accuracy of the results may be found. The procedure has been based on grid refinement until the numerical results agree, within reasonable accuracy, with the analytical ones, obtained from the parallel flow approach developed in the next section. Hence, as shown in Table 1 , a uniform grid of $140 \times 40$ has been selected for $A=8$ (value used for the numerical computations) and has been estimated sufficient to model accurately the flow and temperature fields within the cavity. The time step size, $\delta t$, has been varied in the range $10^{-7} \leq$ $\delta t \leq 10^{-4}$, depending on the values of the governing parameters.

\section{Approximate Parallel Flow Analytical Solution}

As can be seen from Figures 2-4, displaying streamlines (left) and isotherms (right), the flow and temperature fields exhibit a parallel aspect and a linear stratification, respectively, in the most part of the cavity, for $A=8$ and various values of Re, $\mathrm{Ri}$, and $\Phi$. Accordingly, the following simplifications

$$
\begin{gathered}
u(x, y)=u(y), \quad v(x, y)=0, \\
\psi(x, y)=\psi(y), \quad T(x, y)=C\left(x-\frac{A}{2}\right)+\theta(y),
\end{gathered}
$$

where $C$ is unknown constant temperature gradient in the $x$-direction, are possible, which leads to the ordinary nondimensional governing equations:

$$
\begin{gathered}
\frac{d^{3} u}{d y^{3}}=\bar{\alpha} \Omega \operatorname{Re} \operatorname{Ri} \frac{\partial T}{\partial x}=\bar{\alpha} \Omega \operatorname{Re} \operatorname{RiC}, \\
\frac{\bar{\alpha}}{\operatorname{Pe}} \frac{d^{2} \theta}{d y^{2}}=\mathrm{Cu}
\end{gathered}
$$

with

$$
\begin{gathered}
u-1=\frac{d \theta}{d y}=0 \quad \text { for } y=0,1 \\
\int_{0}^{1} u(y) d y=0, \\
\int_{0}^{1} \theta(y) d y=0
\end{gathered}
$$

TABle 1: Accuracy tests conducted with $A=8, \operatorname{Re}=1, \mathrm{Ri}=10^{3}$ and various values of $\Phi$.

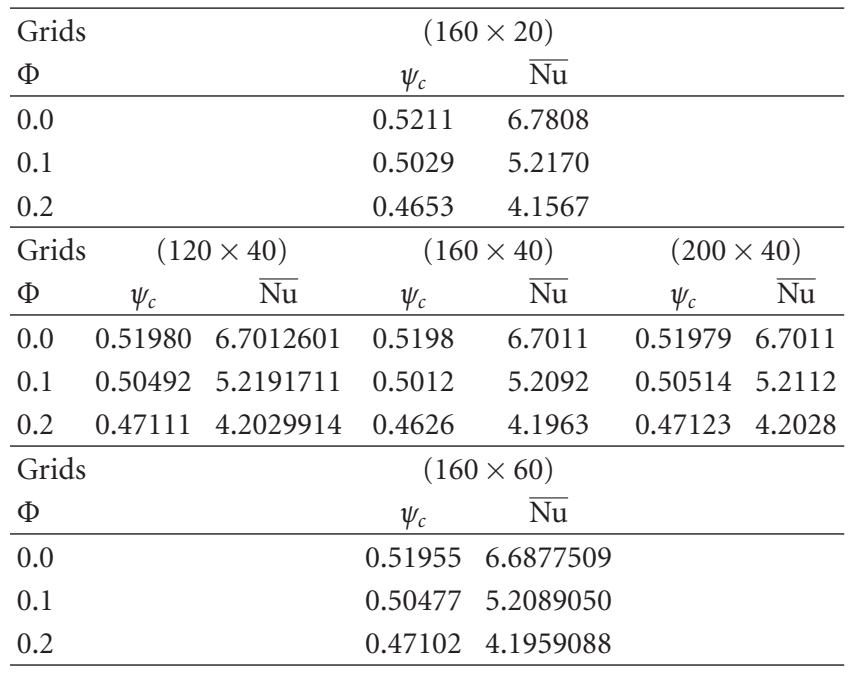

as boundary, return flow, and mean temperature conditions, respectively.

Using such an approach, the solution of (27) and (28), satisfying (29), (30), and (31), is

$$
\begin{gathered}
u(y)=\frac{\bar{\alpha}}{12} \Omega \operatorname{Re} \operatorname{RiC}\left(2 y^{3}-3 y^{2}+y\right)+\left(3 y^{2}-2 y\right) \\
\theta(y)=\frac{1}{12} \Omega \operatorname{RaC} 2\left(\frac{y^{5}}{10}-\frac{y^{4}}{4}+\frac{y^{3}}{6}-\frac{1}{120}\right) \\
+\frac{\operatorname{PeC}}{\bar{\alpha}}\left(\frac{y^{4}}{4}-\frac{y^{3}}{3}+\frac{1}{30}\right) .
\end{gathered}
$$

The expression of the stream function, $\psi(y)$, can be deduced by integration of (19), taking into account the corresponding boundary conditions and (32), which gives

$$
\psi(y)=\frac{\bar{\alpha}}{12} \Omega \operatorname{Re} \operatorname{RiC}\left(\frac{y^{4}}{2}-y^{3}+\frac{y^{2}}{2}\right)+\left(y^{3}-y^{2}\right),
$$

where $\Omega=\bar{\beta} / \bar{\rho} \bar{\alpha} \bar{\nu}$. Therefore, the flow intensity is

$$
\psi_{c}=\left|\psi_{\min }\right|
$$

It corresponds to the maximum value of $|\psi(y)|$ in the central vertical section of the enclosure $(x=A / 2)$.

On the other hand, according to Bejan [22], the energy balance in $x$-direction is

$$
\int_{0}^{1}-\frac{\partial T}{\partial x} d y+\frac{\mathrm{Pe}}{\bar{\alpha}} \int_{0}^{1} u T d y=\int_{0}^{1}-\left(\frac{\partial T}{\partial x}\right)_{x=0 \text { or } A} d y .
$$

In particular, in the parallel flow region and with the application of (16), (36) becomes

$$
-C+\frac{\mathrm{Pe}}{\bar{\alpha}} \int_{0}^{1} u \theta d y=\frac{1}{\bar{k}}
$$




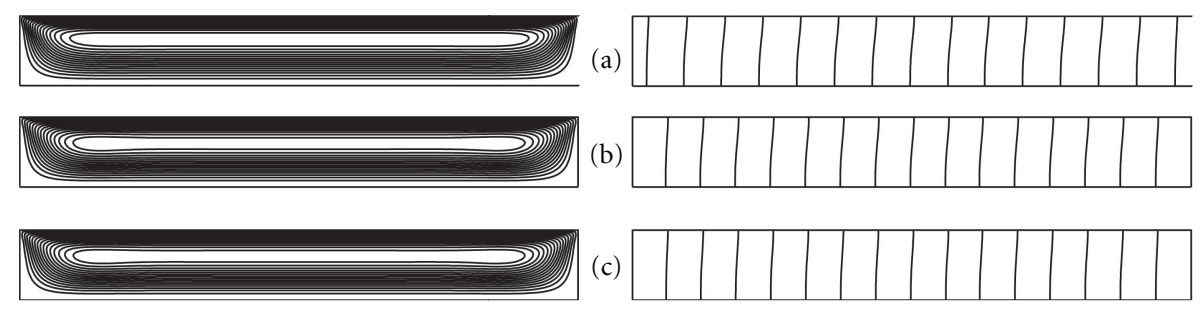

(1)

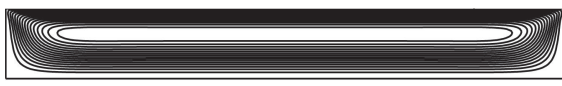

(a)
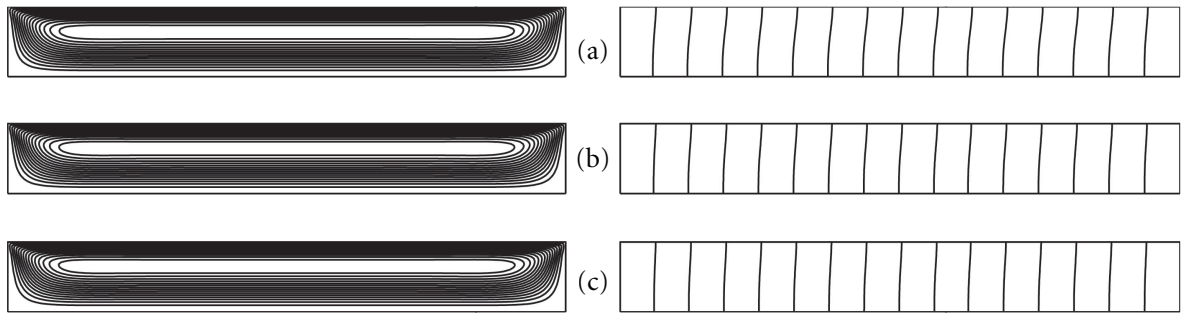

(b)

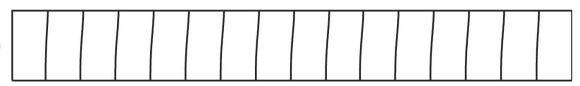

(c)

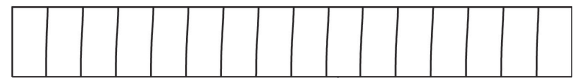

(2)

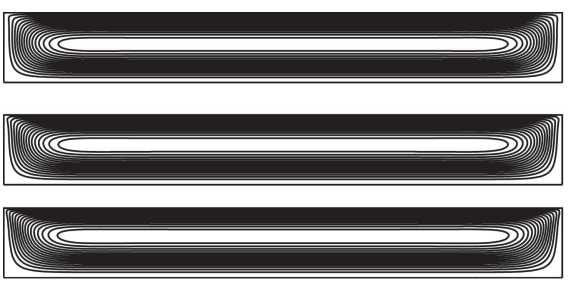

(a)

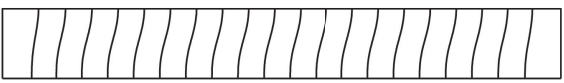

(b)

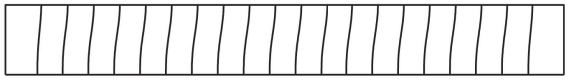

(c)

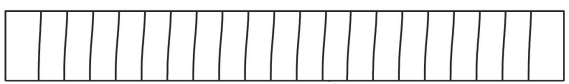

(3)

Figure 2: Streamlines (left) and isotherms (right) for $A=8, \operatorname{Re}=0.1$ and various values of $\Phi((\mathrm{a}) \Phi=0,(\mathrm{~b}) \Phi=0.1$, and (c) $\Phi=0.2)$ and $\operatorname{Ri}\left((1) \mathrm{Ri}=10,(2) \mathrm{Ri}=10^{2}\right.$, and (3) $\left.\mathrm{Ri}=10^{3}\right)$.

which, when substituted to (32) and (33), gives the following transcendental equation:

$$
\frac{1}{\bar{k}}+\left(1+\frac{\mathrm{Pe}^{2}}{105 \bar{\alpha}^{2}}\right) C-\frac{\Omega \mathrm{Pe} \mathrm{Ra}}{3360 \bar{\alpha}} C^{2}+\frac{\Omega^{2} \mathrm{Ra}^{2}}{362880} C^{3}=0
$$

whose solution, via Newton-Raphson method, for given Pe, $\mathrm{Ra}$, and $\Phi$, leads to $C$.

Finally, taking into account (24) and (25), the Nusselt number is constant and can be expressed as

$$
\mathrm{Nu}=\overline{\mathrm{Nu}}=-\frac{1}{C}
$$

\section{Results and Discussion}

The results presented in this paper are limited to copper(Cu-) water nanofluid, whose thermophysical properties of $\mathrm{Cu}$ and water are given in Table 2 [21]. On the other hand, with thermal boundary conditions of uniform heat flux type, the flow field, thermal field, and thermoconvective characteristics become parallel, stratified, and independent on $A$, respectively, in the limit of the explored values of $\mathrm{Re}$, $\mathrm{Ri}, \Phi$, and Pr, when $A$ is large enough. This is the case for $A=8,0.1 \leq \operatorname{Re} \leq 10,10^{-3} \leq \mathrm{Ri} \leq 10^{6}, 0 \leq \Phi \leq 0.2$, and $\operatorname{Pr}=7$ (water-based mixtures). Therefore, the problem of
TABle 2: Thermophysical properties of base fluid $\left(\mathrm{H}_{2} \mathrm{O}\right)$ and nanoparticles $(\mathrm{Cu})[21]$.

\begin{tabular}{lcccc}
\hline & $\rho$ & $C_{P}$ & $k$ & $\beta \times 10^{5}$ \\
& $\mathrm{kgm}^{-3}$ & $\mathrm{~J} \mathrm{~kg}^{-1} \mathrm{~K}^{-1}$ & $\mathrm{Wm}^{-1} \mathrm{~K}^{-1}$ & $\mathrm{~K}^{-1}$ \\
\hline $\mathrm{H}_{2} \mathrm{O}$ & 997.1 & 4179 & 0.613 & 21 \\
$\mathrm{Cu}$ & 8933 & 385 & 401 & 1.67 \\
\hline
\end{tabular}

mixed convection in the enclosure is governed only by three dimensionless parameters, namely, Re, Ri, and $\Phi$, whose effects are largely discussed below.

5.1. Dynamical and Thermal Structures. Typical streamlines (left) and isotherms (right) are displayed in Figures 2-4 for each value of Re and different values of $\mathrm{Ri}$ and $\Phi$. First of all, it is interesting to observe that the flow is unicellular and clockwise, as a result of cooperating aspect of buoyancy and shear effects, which act together from left to right. Also, as mentioned in Section 4, except for the end sides where the flow undergoes a rotation of $180^{\circ}$, this one is parallel to the horizontal boundaries and the temperature is linearly stratified in the horizontal direction. In addition to that, the symmetry of the flow, observed for a dominant buoyancy effect, is generally broken by the shear one. On the other hand, as shown in Figure 2, corresponding to $\operatorname{Re}=0.1$, 


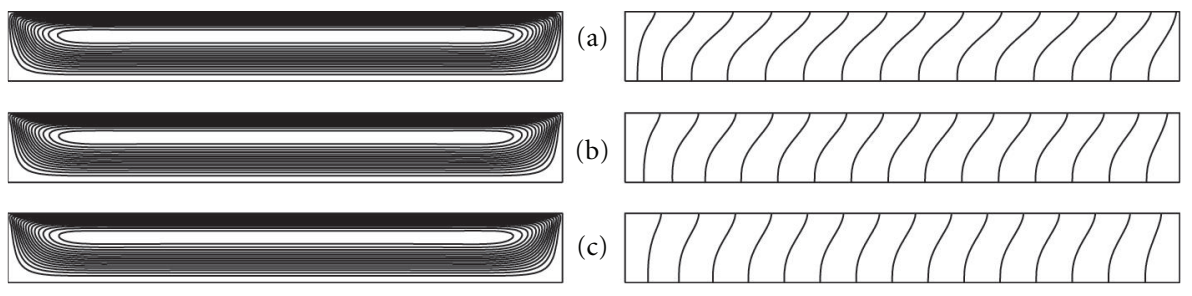

(1)

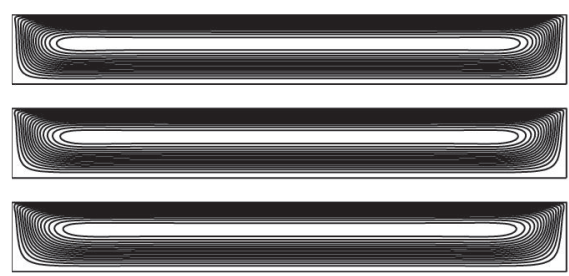

(a)

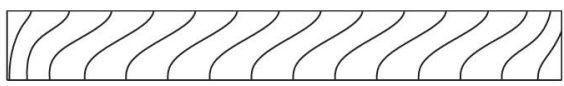

(b)

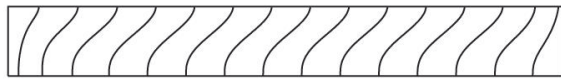

(c)

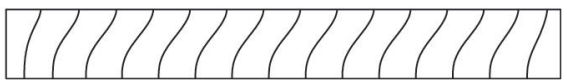

(2)

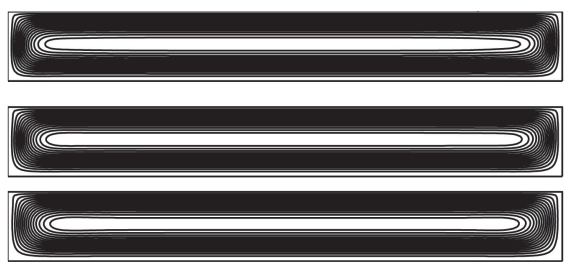

(a)

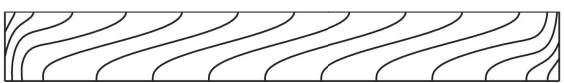

(b)

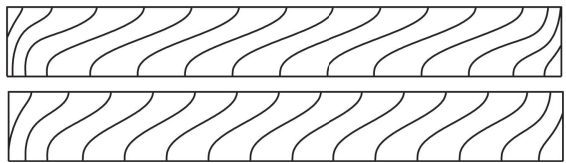

(3)

Figure 3: Streamlines (left) and isotherms (right) for $A=8, \operatorname{Re}=1$ and various values of $\Phi((\mathrm{a}) \Phi=0,(\mathrm{~b}) \Phi=0.1$ and (c) $\Phi=0.2)$ and $\operatorname{Ri}\left((1) \mathrm{Ri}=10,(2) \mathrm{Ri}=10^{2}\right.$ and $(3) \mathrm{Ri}=10^{3}$ ).

the roles of Ri and $\Phi$ are felt only from $\mathrm{Ri}=10^{3}$, but with much more effect for Ri than for $\Phi$, as can be clearly seen from the isotherms, whose inclination with respect to the vertical direction increases importantly with $\mathrm{Ri}$ and decreases slightly with $\Phi$. Below this value, both effects are not sufficient to promote strong convection, and the regime is pseudoconductive with isotherms almost vertical. For $\operatorname{Re}=1$ (Figure 3), the shear effect is so important that the flow symmetry, expressing the buoyancy effect domination, necessitates an important increase of Ri. In fact an augmentation of Ri leads to streamlines less crowded near the top moving wall and isotherms more tilted. In such a situation, the effect of $\Phi$ does not clearly appear on the streamlines, but the isotherms seem affected since their inclination gets lesser with increasing $\Phi$. Hence, the two parameters seem to act oppositely. Finally, for Re = 10 (Figure 4), as before, a progressive increase of Ri makes stronger buoyancy effect, giving rise to an almost symmetric flow characterised by streamlines quasi-equally spaced. Here also, the effect of $\Phi$ cannot be readily detected, from the streamlines. However, the isotherms show a big change with $\mathrm{Ri}$, expressed by an almost flat zone in the most part of the cavity and a boundary layer near the left wall, where they are crowded. In this case, it is easy to see that an increase of $\Phi$ reduces the isotherms inclination and makes thicker the thermal boundary layer, particularly for a small value of Ri.

On the other hand, it is to note that the similarity notion is not respected in the present problem since, for the same values of Ri and $\Phi$, a change of Re may affect significantly streamlines and isotherms.

5.2. Validation of the Approximate Analytical Solution. To check the validity of the approximate analytical solution, the numerical results (full circles) are compared to those obtained analytically (solid lines), as displayed in Figures 5, 6 , and 7 giving stream function (left) and temperature (right) profiles along $y$-axis at the mid length of the cavity, $\psi(A / 2, y)$ and $T(A / 2, y)$, respectively. As can be seen, the two types of results agree well, which confirms the existence of an analytical solution and validates mutually the parallel flow approximation and the computing code.

In addition, analytical and numerical values of the stream function at the vertical central section of the cavity, $\psi_{c}$, and mean Nusselt number, $\overline{\mathrm{Nu}}$, presented in Figures $8,9,10,11$, 12 , and 13 , show also a perfect agreement, when compared to each other, for various values of Re and wide ranges of Ri and $\Phi$.

Let us mention here that the maximum difference between numerical and analytical results does not exceed $1 \%$, for all the explored values of the governing parameters, which makes Figures 5-13 difficult to read. Therefore, there is no need to represent the relative differences and point toward the domains (or conditions) where the error is the largest.

5.3. Stream Function and Temperature Distributions along the Vertical Central Section. Although Figures 5-7 are related to 

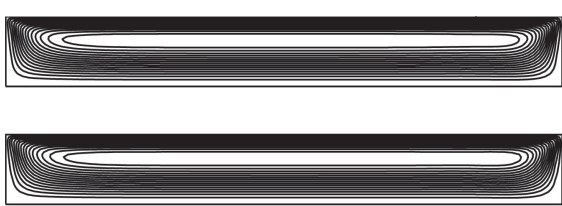

(b)

(a)
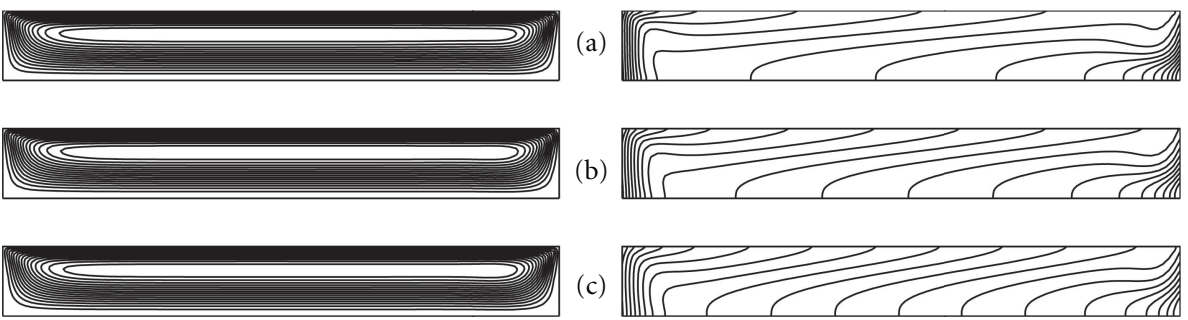

(c)
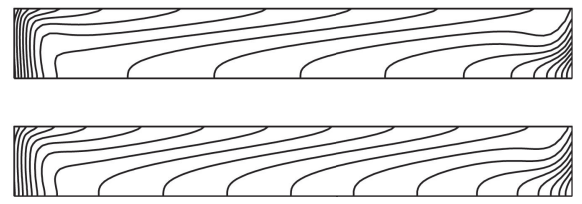

(1)

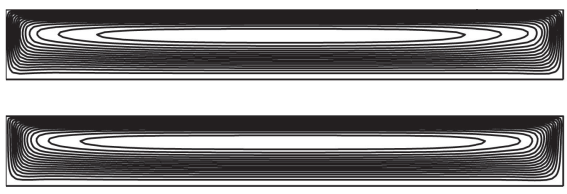

(a)

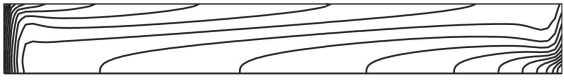

(b)
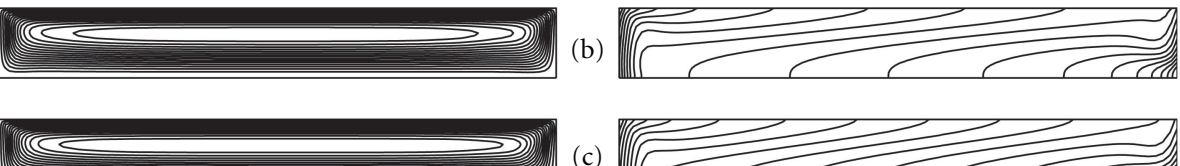

\section{(c)}

(2)
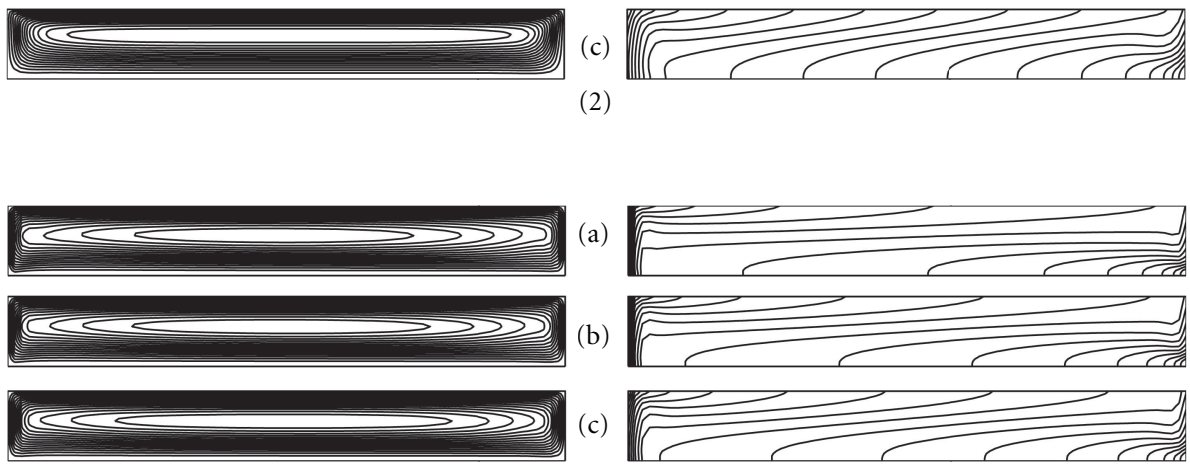

(a)

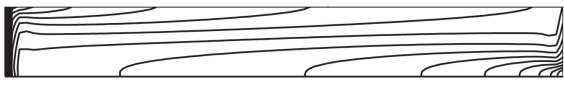

(b)

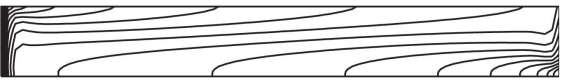

(c)

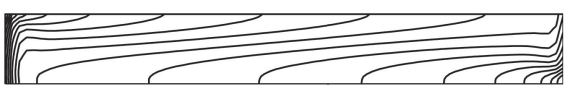

(3)

Figure 4: Streamlines (left) and isotherms (right) for $A=8, \operatorname{Re}=10$ and various values of $\Phi((\mathrm{a}) \Phi=0,(\mathrm{~b}) \Phi=0.1$, and (c) $\Phi=0.2)$ and $\operatorname{Ri}\left((1) \mathrm{Ri}=10,(2) \mathrm{Ri}=10^{2}\right.$, and $\left.(3) \mathrm{Ri}=10^{3}\right)$.

the parallel flow region, they provide enough information on the flow and temperature fields behaviours. Thus, the presence of a single relative minimum in the stream function profile, in all cases, indicates that the flow is unicellular clockwise, driven by both lid and buoyancy cooperating effects. Moreover, the temperature profile presents, in general, two portions, with negative and positive signs, whose amplitude depends on the magnitude of the above-mentioned aiding effects. In fact, the resulting clockwise flow makes warm the top, by transporting the heat from the left hot side, and cold the bottom, after passing near the right cold one, which explains why the sign of the lower portion is negative and that of the upper one is of positive.

These results show, also, the opposing roles of $\mathrm{Ri}$ and $\Phi$, expressed by an increase of $|\psi(A / 2, y)|$ and $|T(A / 2, y)|$ with $\mathrm{Ri}$ and a decrease of these quantities with $\Phi$, except for $\mathrm{Re}=$ 10 (Figure 7) where the role of $\Phi$ becomes insignificant due to the mixing effect induced by the increase of Re (the forced convection neutralises the effect of the effective viscosity caused by the addition of the nanoparticles).

5.4. Flow Intensity and Heat Transfer Rate. The evolution of the flow intensity, $\psi_{c}$ (top), and heat transfer rate, $\overline{\mathrm{Nu}}$ (bottom), which are reported, against Ri, in Figures 8-10, for each Re and various $\Phi$, reveal in general two distinct convection regimes as follows.

(i) A weak convection regime, where $\psi_{c}$ and $\overline{\mathrm{Nu}}$ are nearly constant up to $\mathrm{Ri} \approx 10$. This is related essentially to the fact that the viscosity effect is still dominant for an enclosure of large aspect ratio (shallow enclosure) that inhibits the inertia effects and favours, at the same time, diffusions of momentum and heat.

It should also be noted that the effect of $\Phi$ on $\psi_{c}$, in this regime, is negligible, because of its low circulation, as explained above. In fact, an increase of $\Phi$ leads to an increase of the effective viscosity, which makes more negligible the inertia effects and justifies all this independence of the flow intensity on the concentration of nanoparticles in such a regime. In contrast, increasing $\Phi$ increases $\overline{\mathrm{Nu}}$, due to the fact that the thermal conductivity of nanoparticles is higher than that of the base fluid, but this last finding is valid only for $\operatorname{Re}=0.1$ and 1 (i.e., weak and moderate lid-driven effects). For $\operatorname{Re}=10$, where shear-driven effects are manifest, the tendency is reversed since, this time, $\overline{\mathrm{Nu}}$ decreases with $\Phi$. Indeed, the increase of the viscosity with the nanoparticles concentration results in the increase of the thermal 


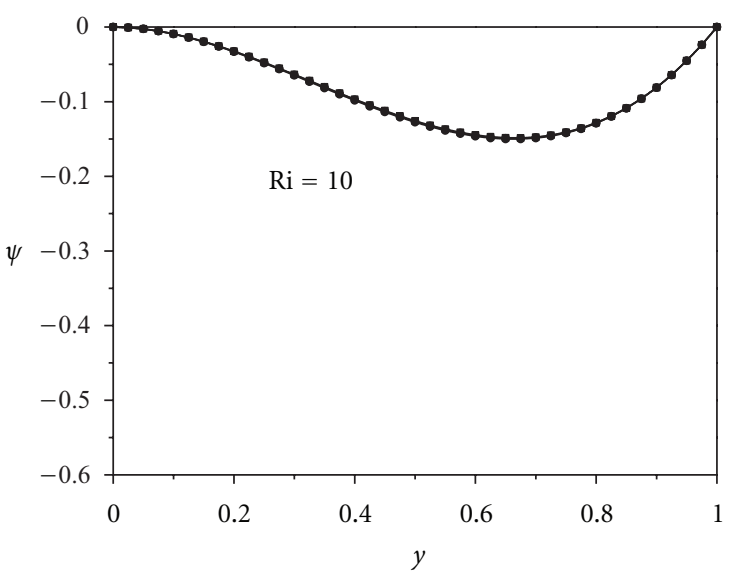

(a)

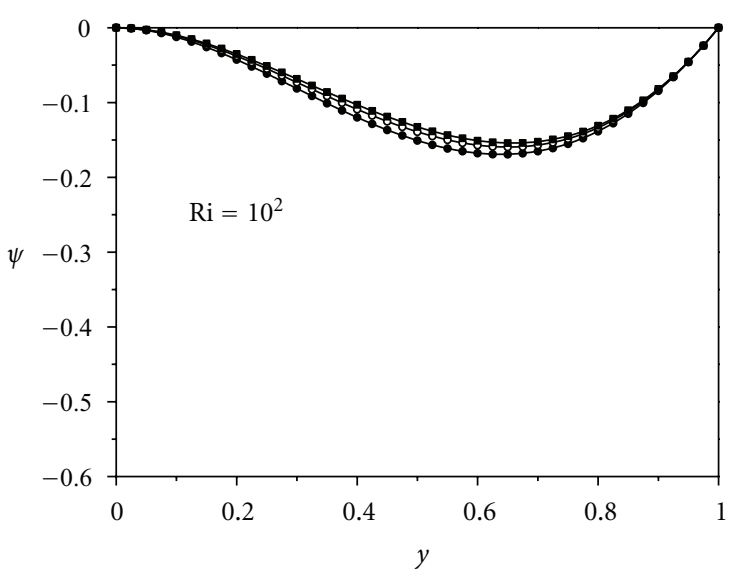

(c)

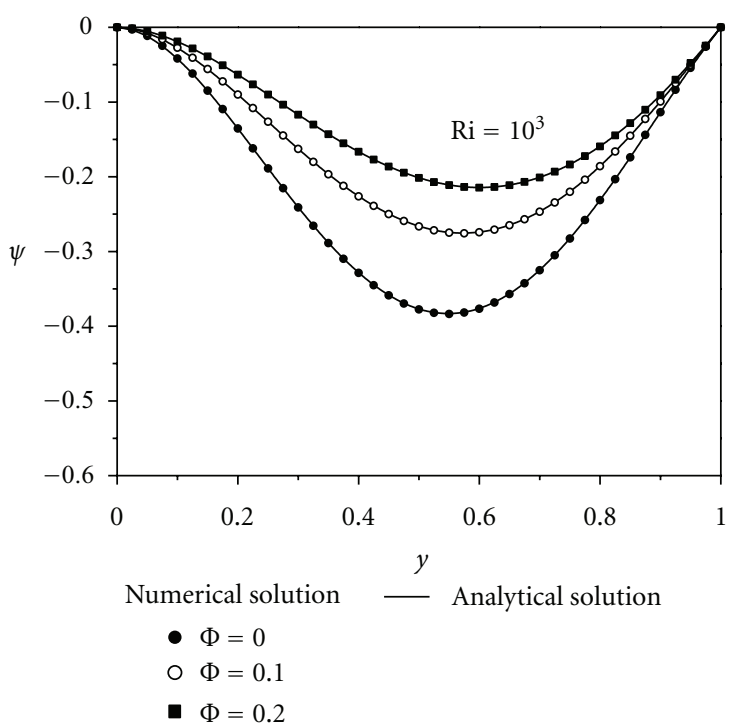

(e)

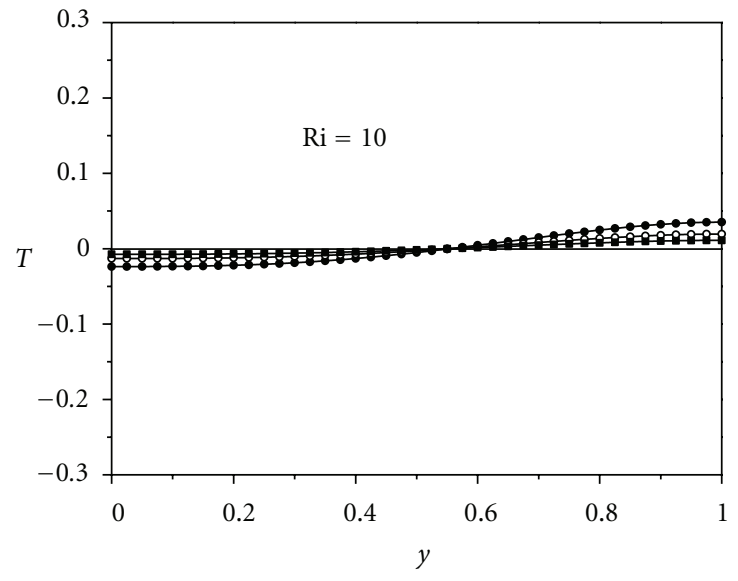

(b)

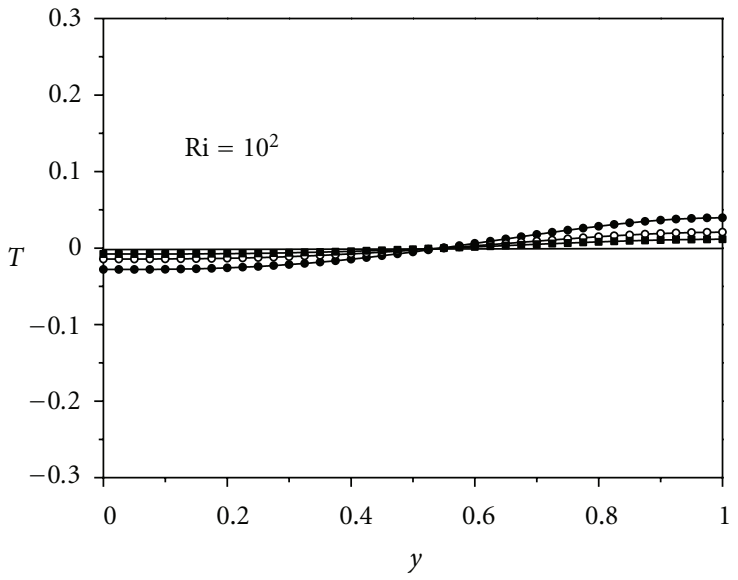

(d)

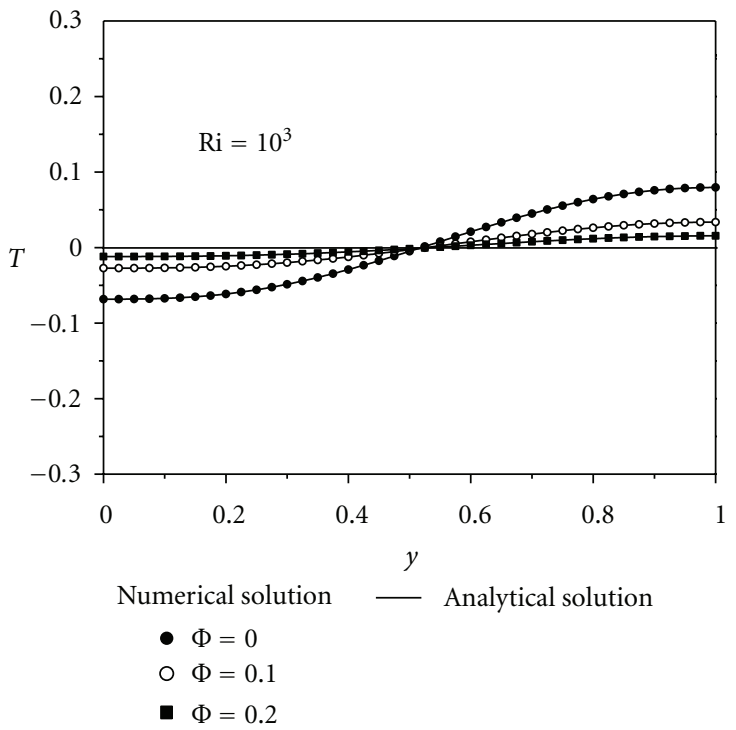

(f)

FIGURE 5: Stream function (left) and temperature (right) profiles at mid length of the cavity, along the vertical coordinate for $A=8, \operatorname{Re}=0.1$ and various values of $\Phi$ and Ri. 


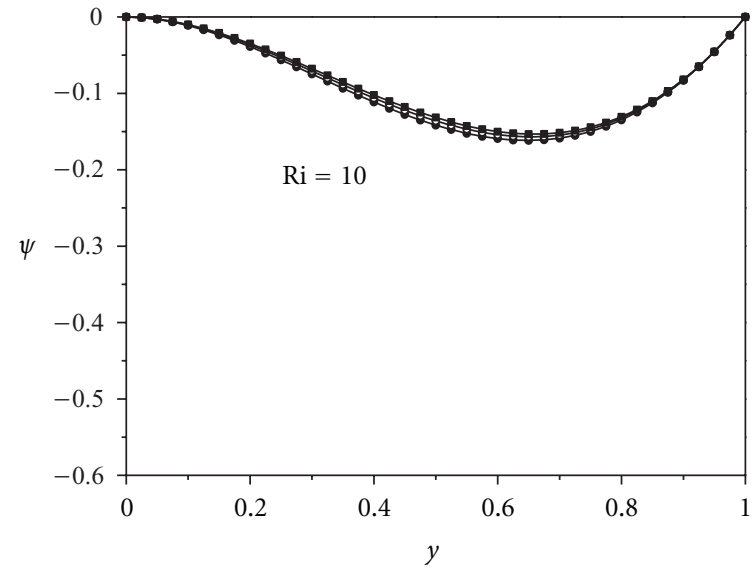

(a)

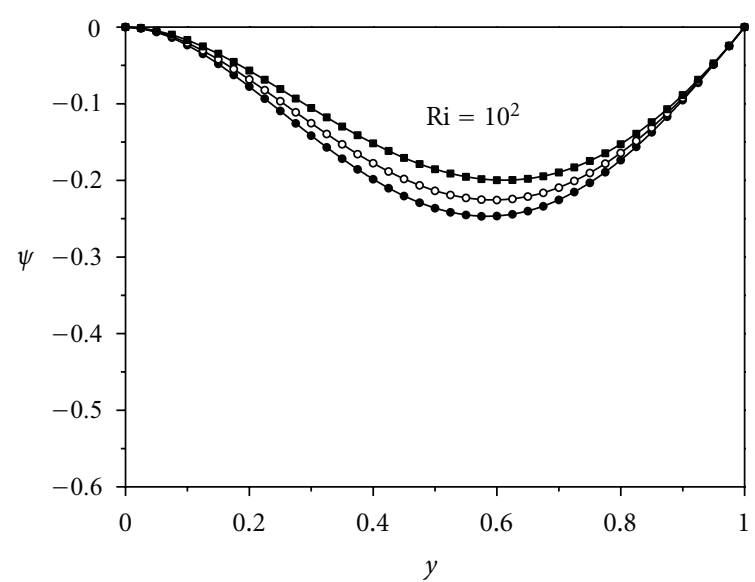

(c)

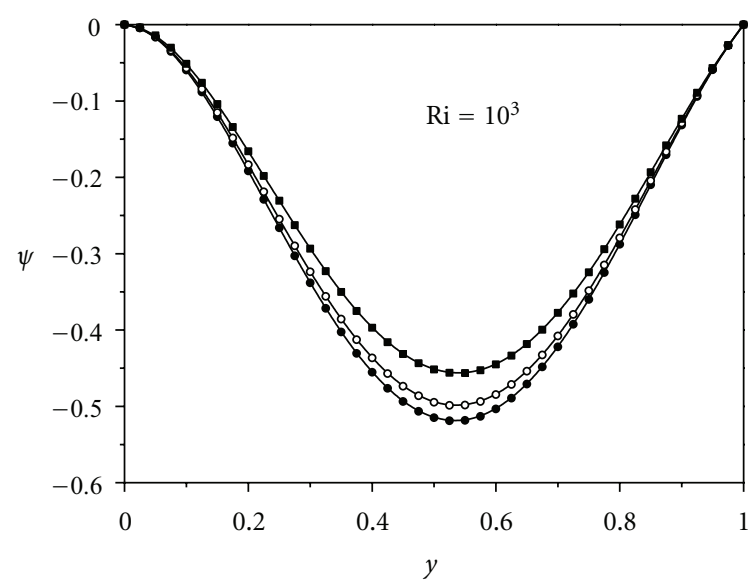

Numerical solution

- $\Phi=0$

$\circ \Phi=0.1$

- $\Phi=0.2$

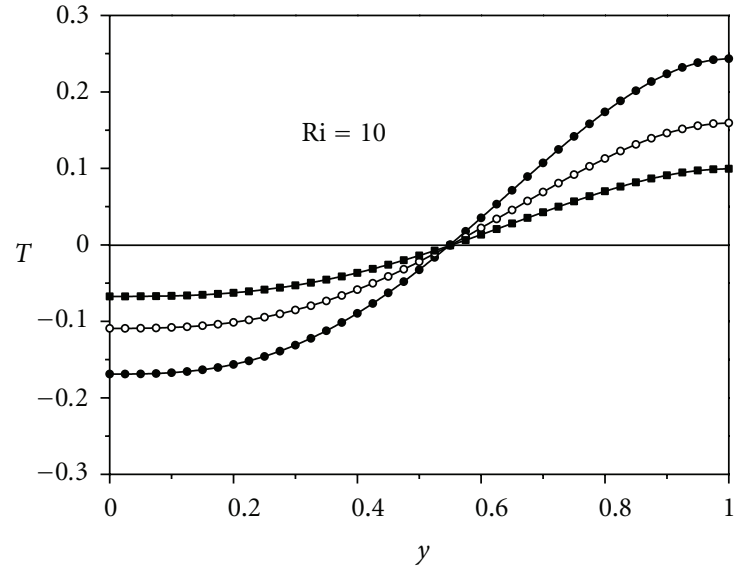

(b)

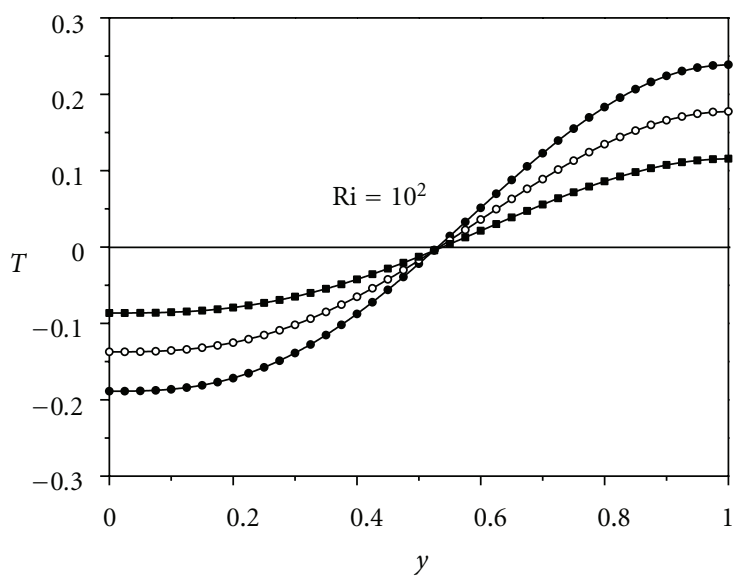

(d)

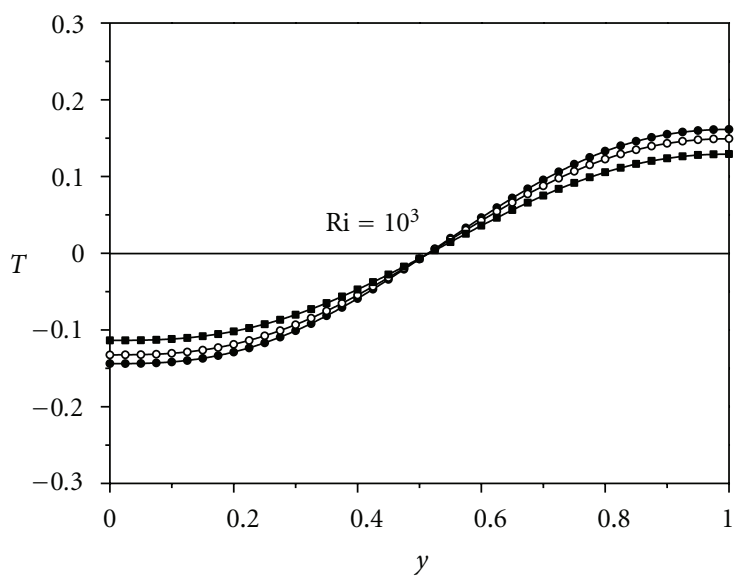

Numerical solution _ Analytical solution

- $\Phi=0$

$\circ \Phi=0.1$

- $\Phi=0.2$

(e)

(f)

Figure 6: Stream function (left) and temperature (right) profiles at mid length of the cavity, along the vertical coordinate for $A=8$, Re $=1$ and various values of $\Phi$ and $\mathrm{Ri}$. 


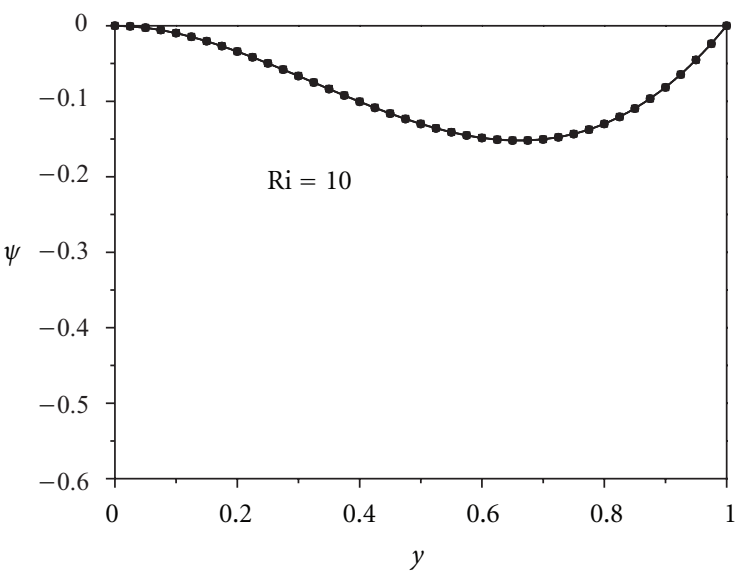

(a)

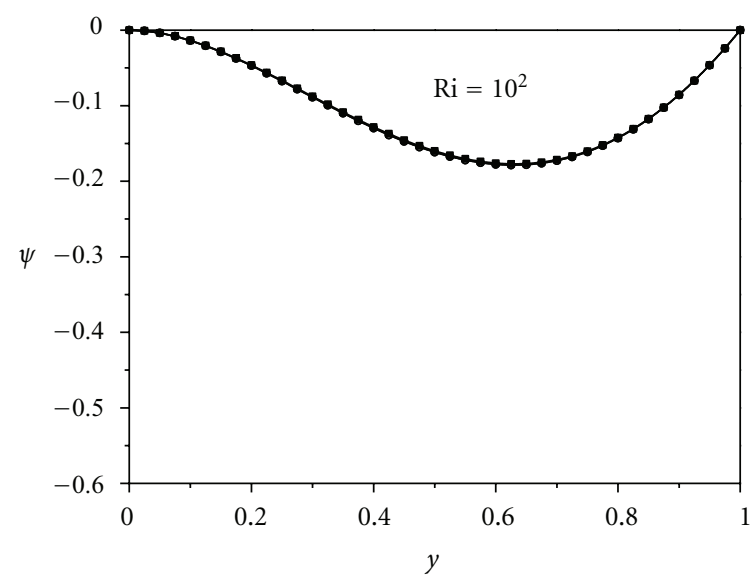

(c)

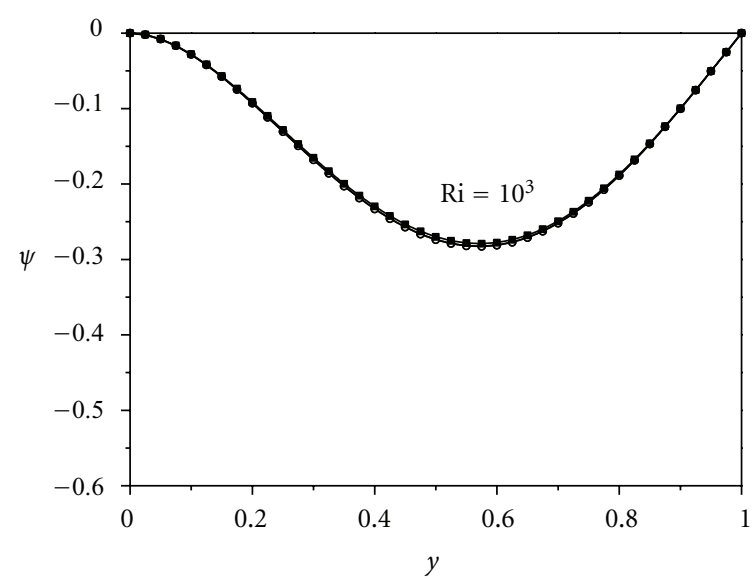

Numerical solution

- $\Phi=0$

$\circ \Phi=0.1$

- $\Phi=0.2$

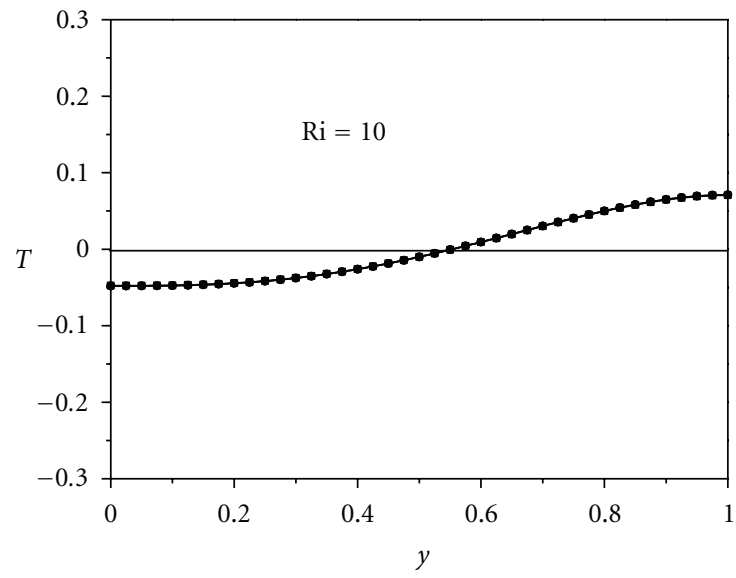

(b)

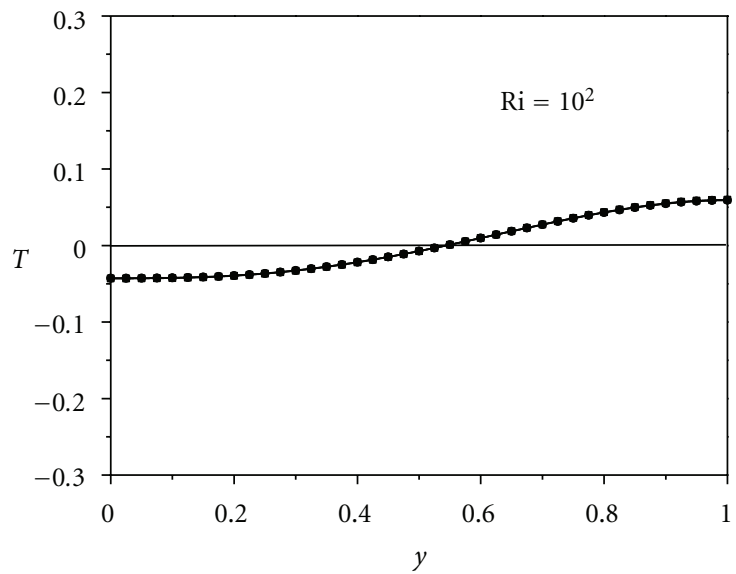

(d)

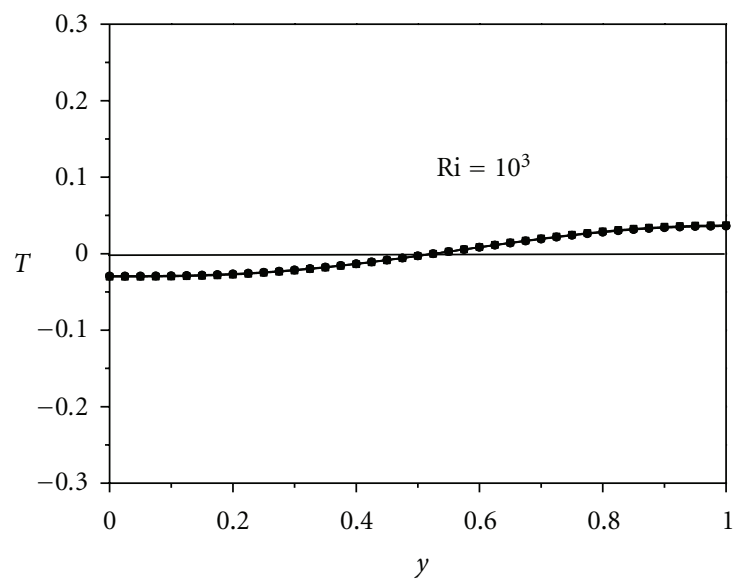

Numerical solution _ Analytical solution

- $\Phi=0$

$\circ \Phi=0.1$

- $\Phi=0.2$

(e)

(f)

FIGURE 7: Stream function (left) and temperature (right) profiles at mid length of the cavity, along the vertical coordinate for $A=8$, Re $=10$ and various values of $\Phi$ and Ri. 


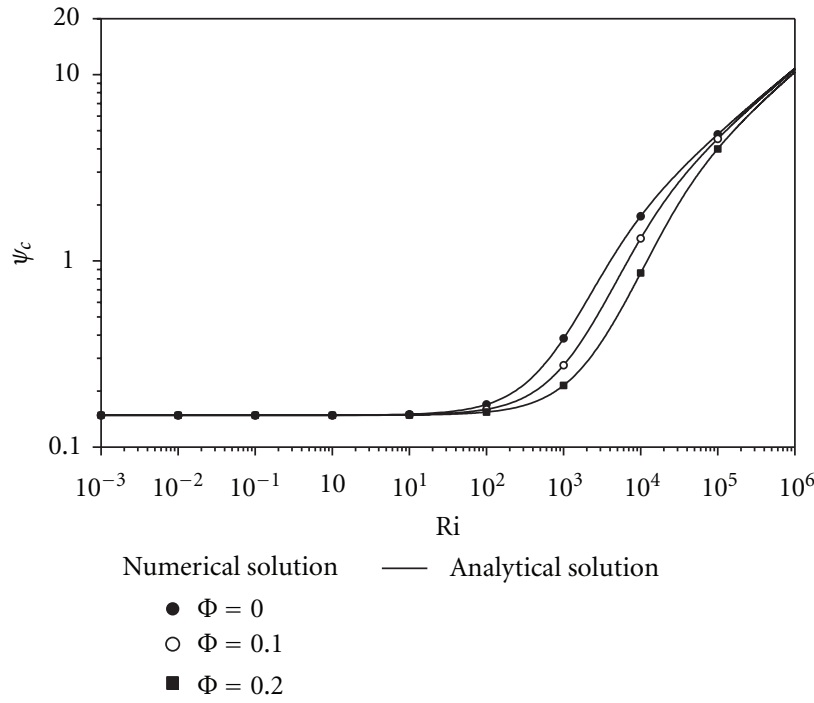

(a)

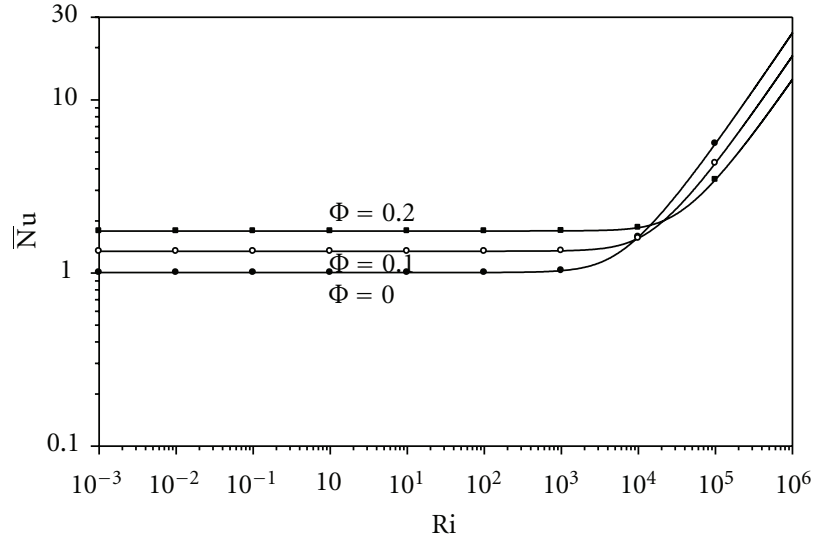

Numerical solution $\quad$ Analytical solution

- $\Phi=0$

○ $\Phi=0.1$

- $\Phi=0.2$

(b)

Figure 8: Evolution of the stream function (a) and the Nusselt number (b), in the central part of the cavity, with Ri, for $A=8, \operatorname{Re}=0.1$ and various values of $\Phi$.

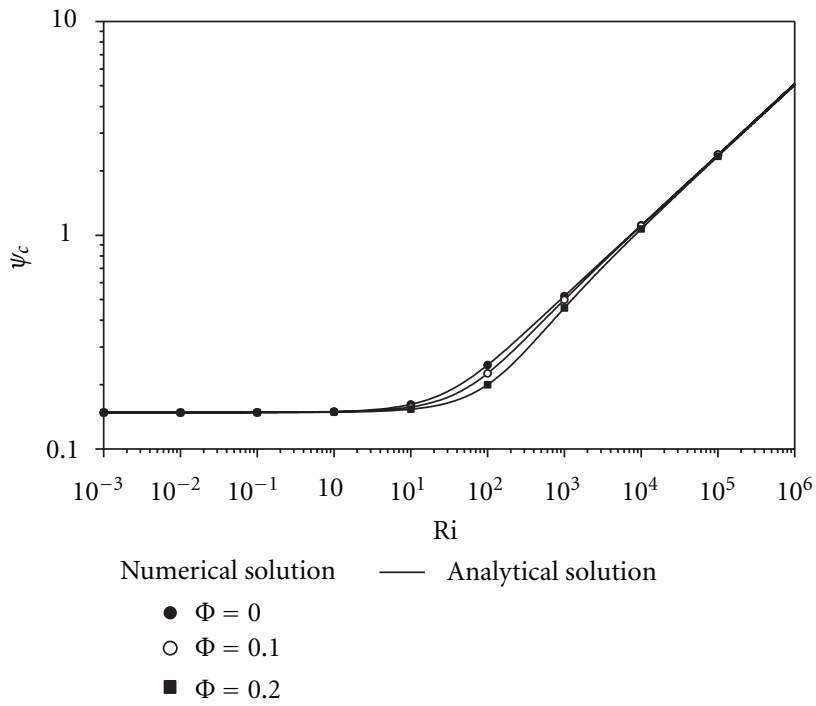

(a)

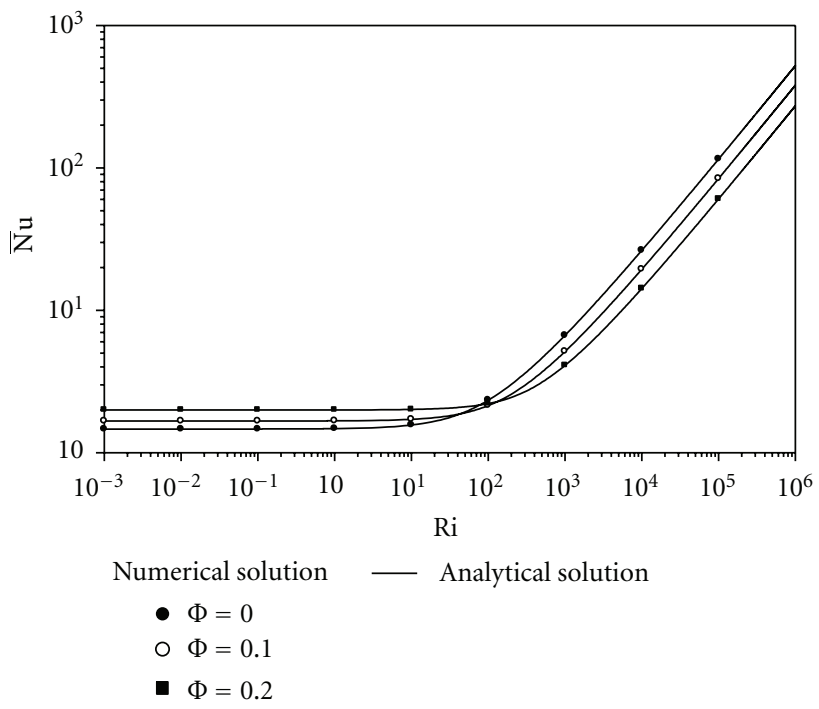

(b)

FIgURE 9: Evolution of the stream function (a) and the Nusselt number (b), in the central part of the cavity, with $\mathrm{Ri}$, for $A=8, \mathrm{Re}=1$ and various values of $\Phi$.

boundary layer thickness, which in its turn is responsible for the diminution of the temperature gradient and thus the augmentation of the thermal resistance, reducing heat transfer accordingly.

(ii) A second regime, dominated by convection, that manifests itself from a value of $\mathrm{Ri}>10$, depending, generally, on both $\Phi$ and Re. Such a regime is characterised by an increase of $\psi_{c}$ and $\overline{\mathrm{Nu}}$ with $\mathrm{Ri}$, which starts slowly to reach an asymptotic linear trend from a certain value of Ri, because buoyancy becomes, gradually, the main driving force for the fluid motion with an increasing Ri. Such particular value of Ri diminishes with Re whatever the value of $\Phi$.

The effect of $\Phi$ is such that an increase of this parameter leads to a decrease of $\psi_{c}$ and $\overline{\mathrm{Nu}}$. For $\psi_{c}$, the reason is that the addition of nanoparticles, in the base fluid, augments the viscosity whose slowing-down role of the motion is well known. This occurs only for a range of $\mathrm{Ri}$ whose expanse reduces with Re. Beyond this range, the inertia of the nanoparticles becomes comparable with that of the fluid, due to large values of Ri, and the effect of $\Phi$ tends to 


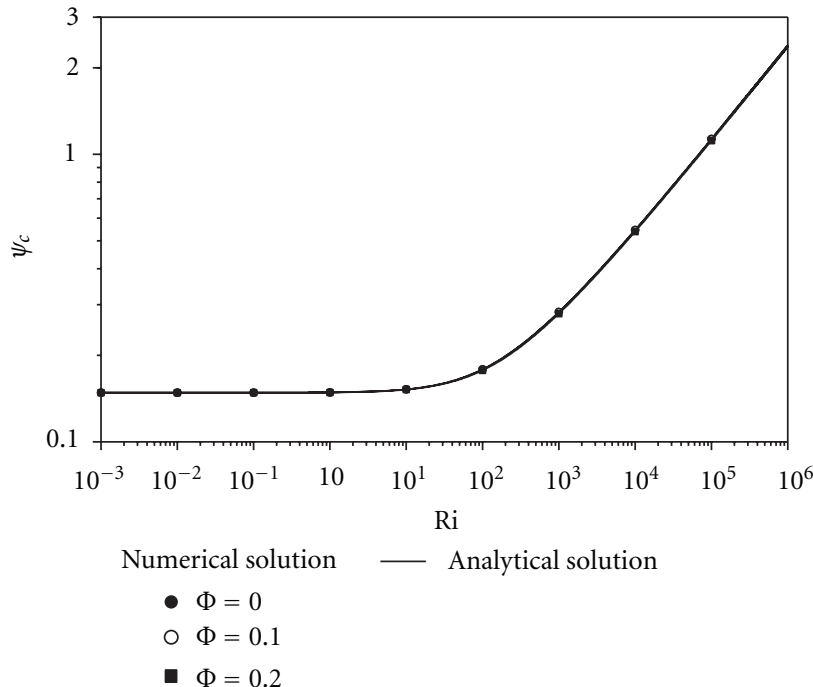

(a)

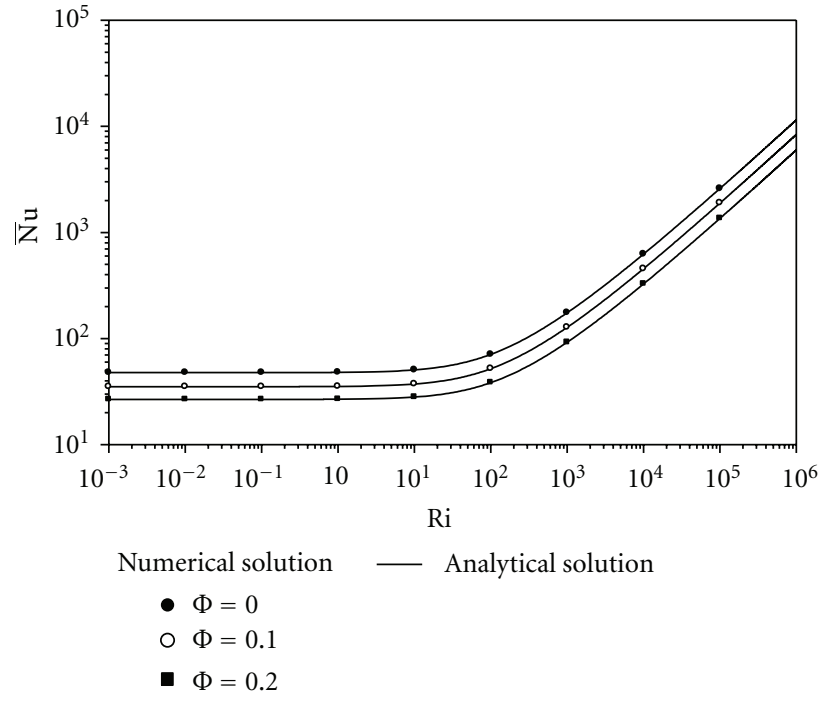

(b)

Figure 10: Evolution of the stream function (a) and the Nusselt number (b), in the central part of the cavity, with Ri, for $A=8, \operatorname{Re}=10$ and various values of $\Phi$.

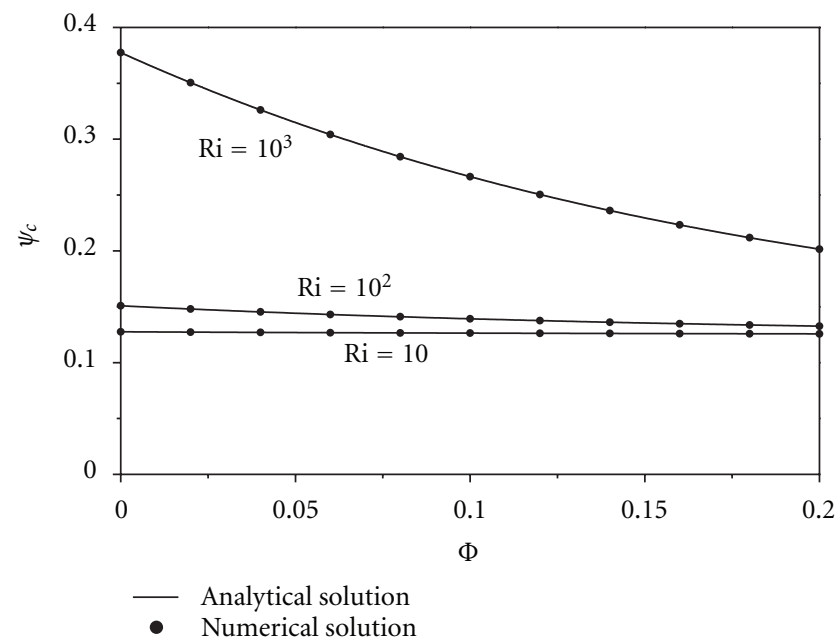

(a)

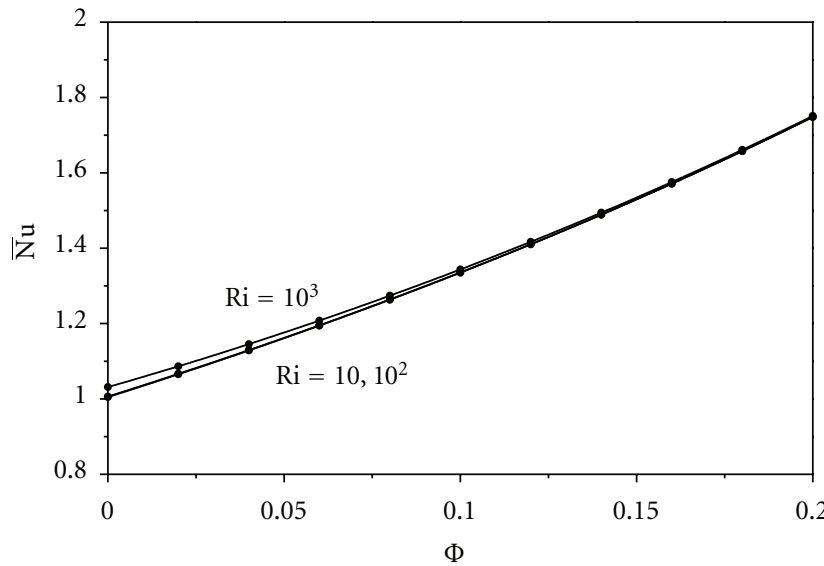

- Analytical solution

- Numerical solution

FIGURE 11: Evolution of the stream function (a) and the Nusselt number (b), in the central part of the cavity, with $\Phi$, for $A=8$, Re $=0.1$ and various values of Ri.

be increasingly insignificant, which explains the meeting of the curves of $\psi_{c}$ in such a situation. For $\overline{\mathrm{Nu}}$, the decrease with $\Phi$ is the consequence of the conflict between effective conductivity and viscosity. In fact, the former tends to enhance heat transfer while the latter tends to reduce it, indirectly, by slowing down the fluid motion, particularly near the thermally active walls, whose role in terms of heat transport is crucial.

Moreover, it is interesting to see that, for $\mathrm{Ri}>10$, an increase of Re leads to a decrease of $\psi_{c}$ and an increase of $\overline{\mathrm{Nu}}$, which means that the shear effect weakens the flow and improves the heat transfer owing to its mixing role.
Another way to examine the effect of $\Phi$ on $\psi_{c}$ (top) and $\overline{\mathrm{Nu}}$ (bottom) is to plot these quantities against $\Phi$ for each value of Re and given values of Ri, as shown in Figures 11-13. Hence, for Re $=0.1$ (Figure 11), the decrease of $\psi_{c}$ with $\Phi$ becomes pronounced while increasing $\mathrm{Ri}$, but such a decrease tends to be lesser (very weak slop) for $\mathrm{Re}=1$ (Figure 12) and ends to disappear for $\operatorname{Re}=10$ (Figure 13) since $\psi_{c}$ stops depending on $\Phi$. As for $\overline{\mathrm{Nu}}$, the tendency is such that $\overline{\mathrm{Nu}}$ starts to increase with $\Phi$ for Re $=0.1$ (Figure 11), tends to decrease with $\Phi$, depending gradually on Ri, for Re = 1 (Figure 12), and finishes to decrease completely with $\Phi$, whatever the selected value of $\mathrm{Ri}$, for $\mathrm{Re}=10$ (Figure 13). 


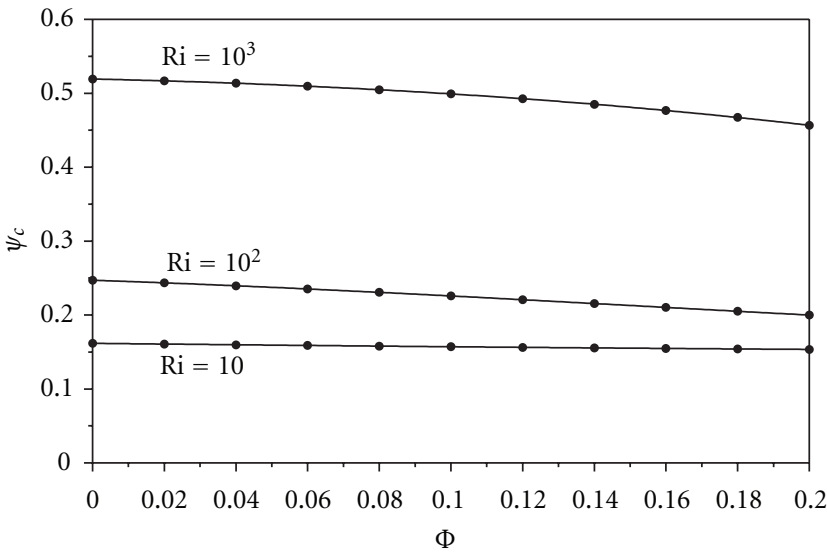

- Analytical solution

- Numerical solution

(a)

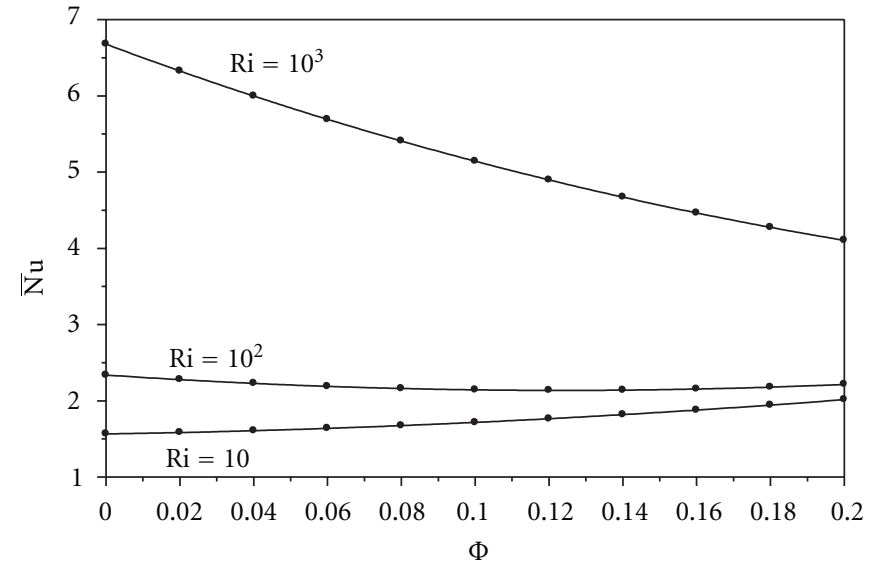

- Analytical solution

- Numerical solution

Figure 12: Evolution of the stream function (a) and the Nusselt number (b), in the central part of the cavity, with $\Phi$, for $A=8$, Re $=1$ and various values of Ri.

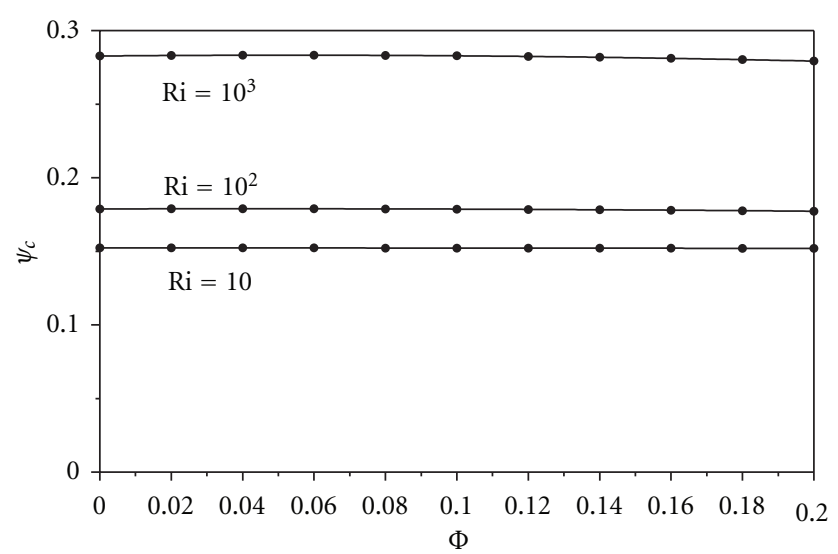

- Analytical solution

- Numerical solution

(a)

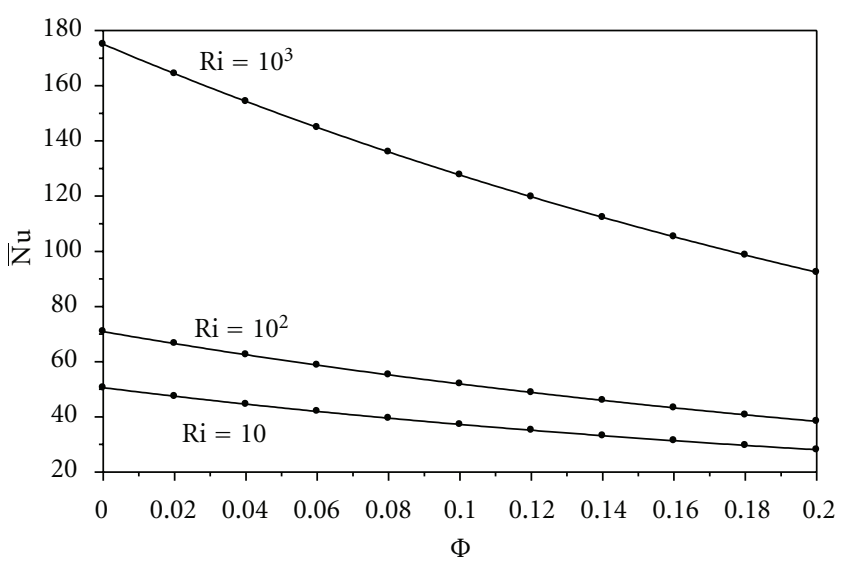

- Analytical solution
Numerical solution

(b)

Figure 13: Evolution of the stream function (a) and the Nusselt number (b), in the central part of the cavity, with $\Phi$, for $A=8, \operatorname{Re}=10$ and various values of $\mathrm{Ri}$.

Consequently, the dependence of $\psi_{c}$ and $\overline{\mathrm{Nu}}$ on $\Phi$ changes with Re and Ri.

\section{Conclusion}

In this paper a numerical and analytical study on mixed convection in a two-dimensional horizontal shallow enclosure, of aspect ratio $A=8$, filled with a nanofluid, has been conducted in the case where both short vertical sides are submitted to uniform heat fluxes while the long horizontal ones are assumed adiabatic, with the top one uniformly moving in the same direction to heat flux.

The full partial differential equations, governing the problem, have been solved numerically using a finite volume method. The computations, which have been limited to $\mathrm{Cu}$ water mixtures, with $\operatorname{Pr}=7$, have been carried out with governing parameters, Re, Ri, and $\Phi$, varying, respectively, in the ranges $0.1 \leq \operatorname{Re} \leq 10,10^{-3} \leq \mathrm{Ri} \leq 10^{6}$, and $0 \leq \Phi \leq 0.2$. Analytical solution is derived on the basis of a parallel flow assumption in the core region of the enclosure.

It emerges, essentially, from such a study that results related to heat transfer in nanofluids lead to contradictory conclusions, depending on the flow nature, thus leaving still unanswered the question if the use of nanoparticle suspensions for mixed convection applications is actually advantageous with respect to pure liquids. This is paradoxical, when nanofluids are expected to improve heat transfer, and can be, probably, related to the conflict between effective conductivity and viscosity with the complicity of the cavity aspect ratio, which is large and favours the effect of viscosity and disfavours that of conductivity. Therefore, more investigations are called for in order to find out the reasons that lead to heat transfer deterioration in nanofluids. 


\section{Nomenclature}

A : Aspect ratio of the cavity

$C$ : Dimensionless temperature gradient in the $x$-direction

$G$ : Gravitational acceleration

Gr: Grashof number

$H^{\prime}$ : Height of the enclosure

$H$ : $\quad$ Heat exchange coefficient

$k$ : $\quad$ Thermal conductivity of fluid

$\bar{k}$ : Dimensionless parameter

$L^{\prime}$ : $\quad$ Length of the rectangular enclosure

Nu: Local Nusselt number

$\overline{\mathrm{Nu}}$ : Average Nusselt number

Pr: Prandtl number

$q^{\prime}$ : $\quad$ Constant heat flux per unit area

Re: Reynolds number

Ri: Richardson number

$t$ : Dimensionless time

$T$ : Dimensionless temperature

$T_{\mathrm{c}}^{\prime}$ : $\quad$ Reference temperature at the geometric centre of the enclosure

$\Delta T^{*}$ : Characteristic temperature

$(u, v)$ : Dimensionless axial and transverse velocities

$U_{0}^{\prime}$ : Lidvelocity

$(x, y)$ : Dimensionless axial and transverse coordinates.

\section{Greek Symbols}

$\alpha$ : Thermal diffusivity

$\bar{\alpha}$ : Dimensionless parameter

$\beta$ : Thermal expansion coefficient

$\bar{\beta}$ : Dimensionless parameter

$\nu$ : Kinematic viscosity

$\bar{v}$ : Dimensionless parameter

$\mu$ : Dynamic viscosity

$\rho$ : Density of base fluid

$\Phi$ : Nanoparticle volume fraction

$\psi$ : Dimensionless stream function

$\Omega$ : Dimensionless parameter.

Superscripts

': Dimensional variable.

\section{Subscripts}

$c$ : Value relative to the centre of the enclosure or critical value

$f$ : Base fluid

$m$ : Minimum value.

$n f$ : Nanofluid

$n p$ : Nanoparticle

*: Characteristic variable.

\section{References}

[1] S. U. S. Choi, "Enhancing thermal conductivity of fluids with nanoparticles," in Developments and Applications of NonNewtonian Flows, D. A. Singer and H. P. Wang, Eds., vol. 66, pp. 99-105, American Society of Mechanical Engineers, New York, NY, USA, 1995.

[2] W. Yu, D. M. France, S. U. S. Choi, and J. L. Routbort, "Review and assessment of nanofluid technology for transportation and other applications," Tech. Rep. ANL/ESD/07-9, Energy Systems Division, Argonne National Laboratory, 2007.

[3] M. Corcione, "Heat transfer features of buoyancy-driven nanofluids inside rectangular enclosures differentially heated at the sidewalls," International Journal of Thermal Sciences, vol. 49, no. 9, pp. 1536-1546, 2010.

[4] L. A. B. Pilkington, "Review lecture: the float glass process," Proceedings of the Royal Society of London Series A, vol. 314, pp. 1-25, 1969.

[5] F. J. K. Ideriah, "Prediction of turbulent cavity flow driven by buoyancy and shear," Journal of Mechanical Engineering Science, vol. 22, no. 6, pp. 287-295, 1980.

[6] J. Imberger and P. F. Hamblin, "Dynamics of lakes, reservoirs, and cooling ponds," Annual Review of Fluid Mechanics, vol. 14, pp. 153-187, 1982.

[7] C. K. Cha and Y. Jaluria, "Recirculating mixed convection flow for energy extraction," International Journal of Heat and Mass Transfer, vol. 27, no. 10, pp. 1801-1812, 1984.

[8] R. K. Tiwari and M. K. Das, "Heat transfer augmentation in a two-sided lid-driven differentially heated square cavity utilizing nanofluids," International Journal of Heat and Mass Transfer, vol. 50, no. 9-10, pp. 2002-2018, 2007.

[9] E. Abu-Nada and A. J. Chamkha, "Mixed convection flow in a lid-driven inclined square enclosure filled with a nanofluid," European Journal of Mechanics B, vol. 29, no. 6, pp. 473-482, 2010.

[10] M. Mahmoodi, "Mixed convection inside nanofluid filled rectangular enclosures with moving bottom wall," Thermal Sciences, vol. 15, no. 3, pp. 889-903, 2011.

[11] M. A. Mansour, R. A. Mohamed, M. M. Abd-Elaziz, and S. E. Ahmed, "Numerical simulation of mixed convection flows in a square lid-driven cavity partially heated from below using nanofluid," International Communications in Heat and Mass Transfer, vol. 37, no. 10, pp. 1504-1512, 2010.

[12] M. Muthtamilselvan, P. Kandaswamy, and J. Lee, "Heat transfer enhancement of copper-water nanofluids in a lid-driven enclosure," Communications in Nonlinear Science and Numerical Simulation, vol. 15, no. 6, pp. 1501-1510, 2010.

[13] H. Nemati, M. Farhadi, K. Sedighi, E. Fattahi, and A. A. R. Darzi, "Lattice Boltzmann simulation of nanofluid in liddriven cavity," International Communications in Heat and Mass Transfer, vol. 37, no. 10, pp. 1528-1534, 2010.

[14] F. Talebi, A. H. Mahmoudi, and M. Shahi, "Numerical study of mixed convection flows in a square lid-driven cavity utilizing nanofluid," International Communications in Heat and Mass Transfer, vol. 37, no. 1, pp. 79-90, 2010.

[15] G. A. Sheikhzadeh, N. Hajialigol, M. E. Qomi, and A. Fattahi, "Laminar mixed convection of $\mathrm{Cu}$-water nano-fluid in two sided lid-driven enclosures," Journal of Nanostructures, vol. 1, pp. 44-53, 2012.

[16] A. Karimipour, M. Afrand, and M. M. Bazofti, "Periodic mixed convection of a nanofluid in a cavity with top lid sinusoidal motion," International Journal of Mechanical and Materials Engineering, vol. 71, pp. 135-140, 2010.

[17] Y. Xuan and W. Roetzel, "Conceptions for heat transfer correlation of nanofluids," International Journal of Heat and Mass Transfer, vol. 43, no. 19, pp. 3701-3707, 2000.

[18] E. B. Öğüt, "Natural convection of water-based nanofluids in an inclined enclosure with a heat source," International Journal of Thermal Sciences, vol. 48, no. 11, pp. 2063-2073, 2009. 
[19] M. Lamsaadi, M. Naïmi, and M. Hasnaoui, "Natural convection heat transfer in shallow horizontal rectangular enclosures uniformly heated from the side and filled with non-newtonian power law fluids," Energy Conversion and Management, vol. 47, no. 15-16, pp. 2535-2551, 2006.

[20] S. V. Patankar, Numerical Heat Transfer and Fluid Flow, Hemisphere, Washington, DC, USA, 1980.

[21] E. Abu-Nada, Z. Masoud, and A. Hijazi, "Natural convection heat transfer enhancement in horizontal concentric annuli using nanofluids," International Communications in Heat and Mass Transfer, vol. 35, no. 5, pp. 657-665, 2008.

[22] A. Bejan, "The boundary layer regime in a porous layer with uniform heat flux from side," International Journal of Heat and Mass Transfer, vol. 26, no. 9, pp. 1339-1346, 1983. 

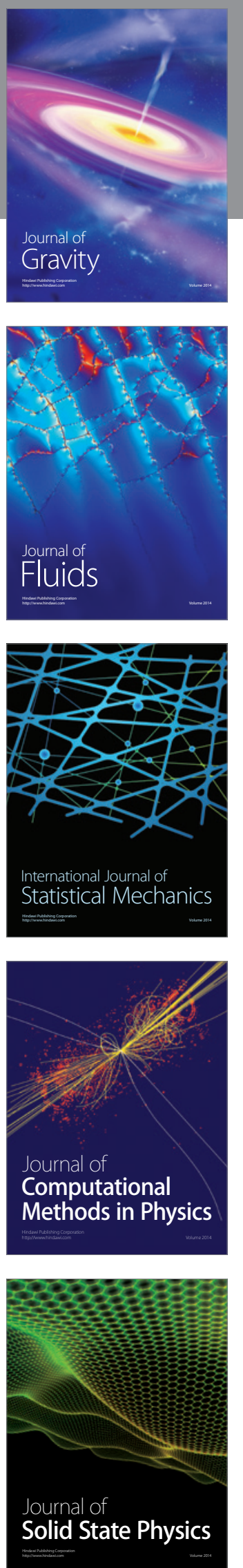
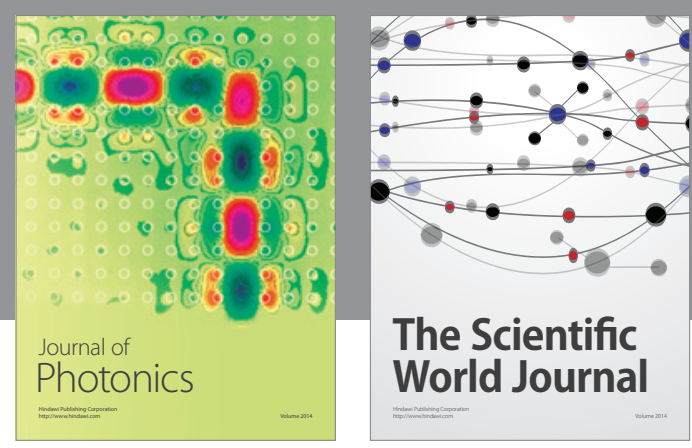

The Scientific World Journal

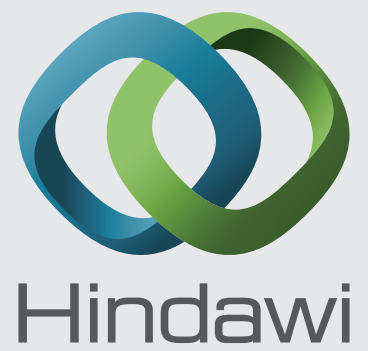

Submit your manuscripts at http://www.hindawi.com
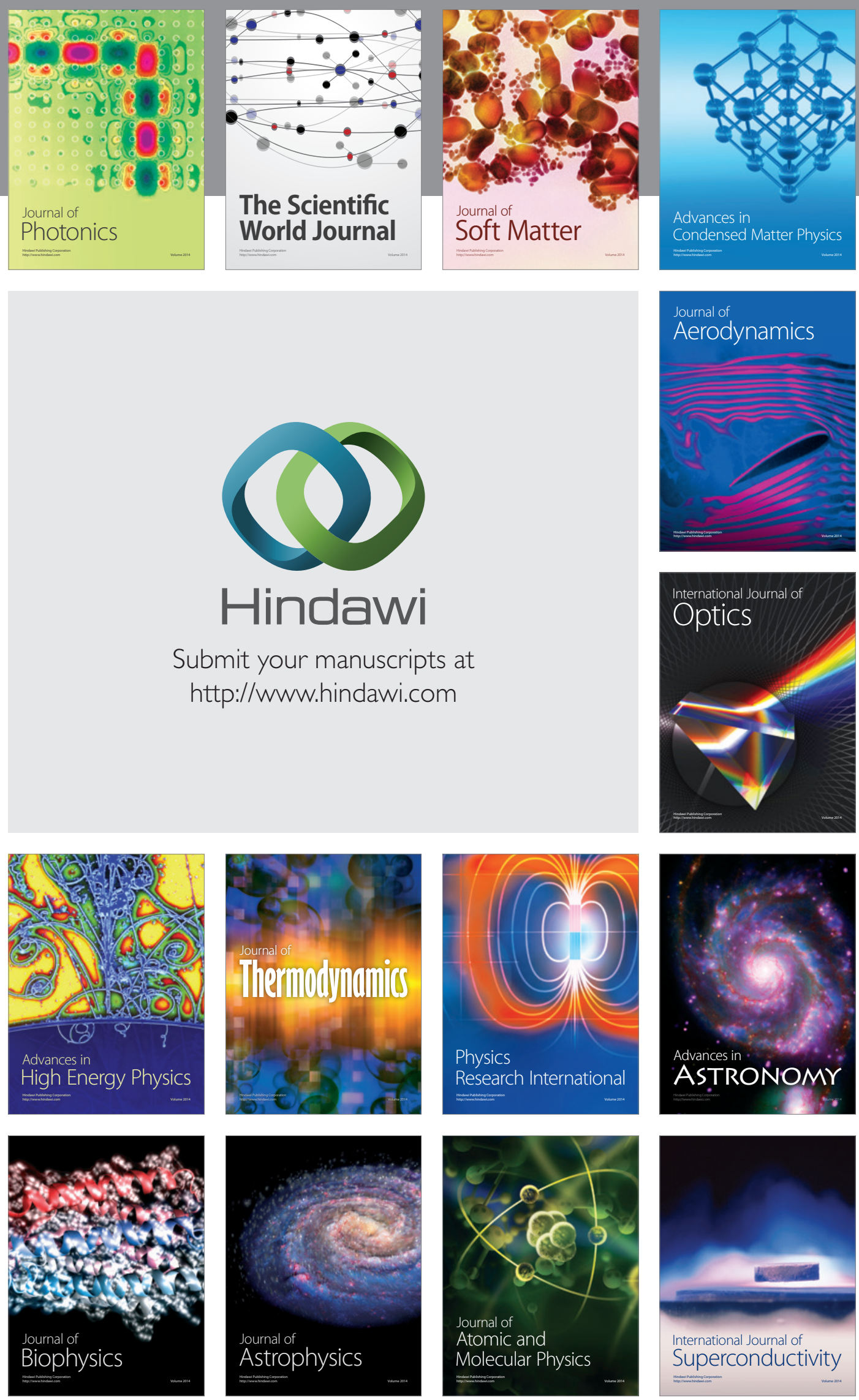
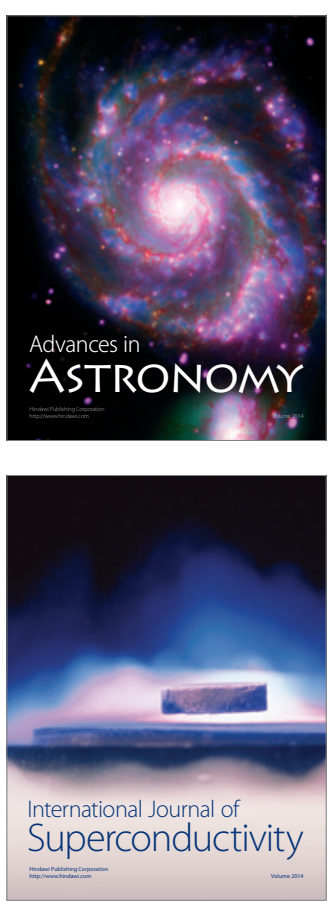